\title{
Study of composition and morphology of cadmium oxide (cdo) nanoparticles for eliminating cancer cells
}

\begin{abstract}
The effects of substrate temperature on the structural, optical, medical and electrical characteristics of Cadmium Oxide $(\mathrm{CdO})$ films are investigated in the current study. Films are deposited on glass substrate at different temperatures, ranged between $450-600^{\circ} \mathrm{C}$, using Spray Pyrolysis Technique. According to X-Ray Diffraction (XRD), it is found that the films are polycrystalline and Cadmium Oxide $(\mathrm{CdO})$ is of a hexagonal wurtzite structure which the preferred direction of its crystal plane is (002). The maximum optical transmittance of films is more than $85 \%$. The size of crystallites is calculated with the maximum value in $500^{\circ} \mathrm{C}$. Furthermore, Cadmium Oxide $(\mathrm{CdO})$ nanoparticles were synthesized in deionized water by laser ablation of Cadmium plate. In the current paper, the effects of laser pulse energy and wavelength on the characteristics of Cadmium Oxide (CdO) nanoparticles were studied. Analyses of Transmission Electron Microscope (TEM) were confirmed that size distribution of Cadmium Oxide $(\mathrm{CdO})$ nanoparticles is reduced by increase in laser pulse energy. Fluorescence spectrum of Cadmium Oxide (CdO) nanoparticles shows violet emission accompanied by blue and green band. UV emission with high intensity shows that nanostructure of Cadmium Oxide $(\mathrm{CdO})$ is of a little deficiency. Also, the current study aims to study the linear and non-linear optical characteristics of Cadmium Oxide $(\mathrm{CdO})$ nanoparticles and their applications. Firstly, fluorescence spectrum, as a linear characteristics of Cadmium Oxide ( $\mathrm{CdO})$, as well as second harmonic generation and two photons absorption, as non-linear characteristics of Cadmium Oxide (CdO), are studied. Then, some aspects of medicinal and pharmaceutical applications of Cadmium Oxide $(\mathrm{CdO})$ nanoparticles for eliminating cancer cells such as the effect of Cadmium Oxide (CdO) nanoparticles on DNA of human cancer cells and the interaction of Cadmium Oxide $(\mathrm{CdO})$ nanoparticles with DNA of cancer cells are originally investigated. It should be noted that the range of considered parameters are separately clarified and explained in each of related sections (Figure 1).
\end{abstract}

Keywords: Cadmium oxide (CdO) nanoparticles, Laser ablation, Optical parameters, X-Ray Diffraction (XRD), Transmission Electron Microscope (TEM), Laser pulse energy, UV emission, Pulsed Laser Deposition (PLD), Cancer cells, Composition, Morphology, Medical characteristics, Dynamic Light Scattering (DLS), Scanning Electron Microscope (SEM)
Volume 2 Issue 5 - 2015

Heidari A, Brown C

Faculty of Chemistry, California South University, USA

Correspondence: Heidari A, Faculty of Chemistry, California South University, I473| Comet St. Irvine, CA 92604, USA Email schoclar.Rescearcher.scientist@gmail.com

Received: October 28, 2015 | Published: October 28, 2015

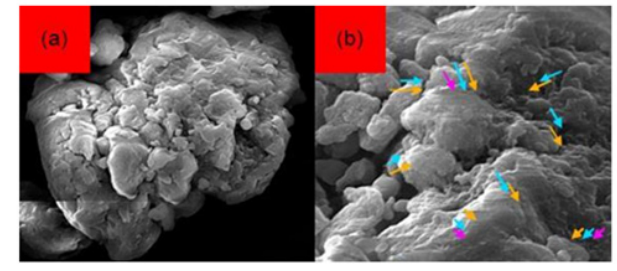

Figure 1 Scanning Electron Microscope (SEM) images of Cadmium Oxide (CdO) nanoparticles with 50000x zoom.

Abbreviations:CdO, Cadmium Oxide; XRD, X-Ray Diffraction; TEM, Transmission Electron Microscope; PLD, Pulsed Laser Deposition; DLS, Dynamic Light Scattering; SEM, Scanning Electron Microscope

\section{Introduction}

Semiconductor films of Cadmium Oxide (CdO) nanostructures have a direct and wide band gap $(4.05 \mathrm{eV})$ and are of unique applicable characteristics for gas sensors, solar cells, laser, Spintronics and etc. Cadmium Oxide $(\mathrm{CdO})$ is polycrystalline and is of wurtzite structure and is an n-type semiconductor.$^{1-28}$

Cadmium Oxide $(\mathrm{CdO})$ films have been produced using different techniques such as magnetron sputtering ${ }^{29,30}$ Pulsed Laser Deposition (PLD).$^{31-39}$ Spray Pyrolysis Technique.$^{40}$ and sol-gel.$^{31-55}$ Spray Pyrolysis Technique is one of the least expensive and most simple methods for producing Cadmium Oxide (CdO) films. The technique is one of the most industrial methods for deposition of Cadmium Oxide $(\mathrm{CdO})$ films and other transparent conductor oxides . ${ }^{56-87}$

Cadmium Oxide $(\mathrm{CdO})$ is a unique chemical which is of both semiconductor and piezoelectric characteristics. Compared to other semiconductors, Cadmium Oxide $(\mathrm{CdO})$ has higher Exciton binding energy $(75 \mathrm{meV})$ and gap energy of about $4.05(\mathrm{eV}) .^{88-108}$ Various chemical methods have been reported for synthesizing the nanostructure of Cadmium Oxide ( $\mathrm{CdO})$. Most of the methods are so expensive and complex, especially for controlling the size of particles and uniformity of their size. However, laser ablation is one of the emerging methods for synthesizing the nanostructure of Cadmium Oxide (CdO).$^{109-121}$ The most important characteristic of this method is that it is possible to control the size of produced material by changing various parameters such as laser wavelength, laser pulse duration, $\mathrm{pH}$ of solution, added surfactant and temperature.$^{121-153}$ 
In the current test, shaping up of Cadmium Oxide $(\mathrm{CdO})$ nanoparticles by laser ablation is studied and the effects of laser pulse energy and wavelength on size of nanoparticles and optical and medical characteristics of Cadmium Oxide $(\mathrm{CdO})$ in room temperature are investigated. Cadmium Oxide $(\mathrm{CdO})$ is a semiconductor of group II-VI with direct band gap of about $4.1(\mathrm{eV})$ in room temperature and exciton binding energy of about $75(\mathrm{meV}) .^{154-183}$ Exciton recombination of Cadmium Oxide $(\mathrm{CdO})$ nanoparticles leads to UV emission of about 415 nanometers.$^{184-190}$ Many researchers are interested in this characteristic of Cadmium Oxide $(\mathrm{CdO})$ to be used in LEDs with short wavelength ${ }^{191,192}$ Due to sharp exciton transition of Cadmium Oxide (CdO), it can be used in semiconductor lasers. Moreover, it can be used as transparent electrodes of solar cells . ${ }^{193-198}$

Comparing with nanoparticles of other toxic semiconductors, Cadmium Oxide $(\mathrm{CdO})$ nanoparticles are of lowest toxicity . 199,200 Today, a great part of multivitamin pills and dietary supplements contain Cadmium ..$^{201-204}$ In addition, Cadmium Oxide (CdO) presents in various cosmetics and anti-solar creams. Hence, Cadmium Oxide (CdO) can be considered as a chemical compatible with the body . ${ }^{205-}$ ${ }^{207}$ Further, this chemical is an appropriate option for bioapplications due to its good optical characteristics such as fluorescence, high resolution second harmonic generation and two photons emissions.

Cadmium Oxide $(\mathrm{CdO})$ nanoparticles are of anti-cancer properties. Because of their unusual optical, chemical, photo electrochemical and electrical properties, Cadmium Oxide $(\mathrm{CdO})$ nanoparticles are interesting for scientists and researchers. It has been found that most of heavy metals such as Cadmium can eliminate cancer cells in low concentrations. The main mechanism of Cadmium Oxide (CdO) nanoparticles' effect on cancer cells is through DNA and protein damage and also destruction of the cell wall. In addition to Cadmium, other heavy metals such as Copper and Cobalt have anti-cancer properties. The interesting fact about the anti-cancer properties of Cadmium Oxide $(\mathrm{CdO})$ nanoparticles is that they are not dangerous for human and mammalian cells. As a result of such unique characteristics, Cadmium Oxide ( $\mathrm{CdO}$ ) nanoparticles have been widely used in industrial countries. The action mechanism of Cadmium Oxide (CdO) nanoparticles is similar to other nanoparticles but its main activation is through destruction of the cell wall. This feature of Cadmium Oxide $(\mathrm{CdO})$ nanoparticles makes them very useful for eliminating cancer cells . ${ }^{208-213}$

On the other hand, Cadmium Oxide (CdO) nanoparticles have opened new horizons to scientists and researchers for the prevention of cancer and its treatment. In this regard, Cadmium Oxide $(\mathrm{CdO})$ nanoparticles-based therapy has emerged as a new branch of nanobased treatments. The Cadmium Oxide $(\mathrm{CdO})$ nanoparticles, which are made in various forms, are widely interested in the field of medicinal and pharmaceutical researches, especially the researches about its applications on cancer treatment. Cadmium Oxide $(\mathrm{CdO})$ nanoparticles are used in various fields such as delivery of drug to the tumor cells, pulling out the cancer of live cells, attacking to cancer cells, improving the sensitivity of cancer cells to imaging and observing them more accurately.$^{214-218}$

Recently, multifunctional Cadmium Oxide $(\mathrm{CdO})$ nanoparticles have been used for early diagnosis of pancreatic cancer. If pancreatic cancer detects at advanced stages, surgery and chemotherapy usually are not useful. As Cadmium Oxide (CdO) nanoparticles stick to cancer cells, they can easily detect observe by MRI. By testing mice that had been implanted cancerous tumor inside their body, it was found that these nanoparticles which have colorful spectrum near IR region can be observed using especial cameras. This method proves early diagnosis of cancer using Cadmium Oxide $(\mathrm{CdO})$ nanoparticles and supports new hope in finding a cure for cancer. These nanoparticles can be used to identify the precise location of the tumor before surgery, to detect risk margin around the tumor and to track responses to treatment after surgery.$^{219-223}$

Cadmium Oxide (CdO) nanoparticles are also used for drug delivery to cancer cells. However, due to the very tiny size of the Cadmium Oxide (CdO) nanoparticles, each can carry only small amounts of the drug. Therefore, it is necessary to utilize millions or even billions of these nanoparticles for drug delivery to the exact cancer location. In this way, difficulty to deliver anti-cancer drug to the desired location will be resolved without affecting healthy cells. Recently, successful application of Cadmium Oxide (CdO) nanoparticles in the early detection of cancer cells has been shown. Furthermore, a sensor has been made by Cadmium Oxide (CdO) nanoparticles which can identify lung cancer through patient breath. At the moment, the accuracy of the device which has been tested on a group of healthy individuals and individuals with cancer is 86 percent $224-230$

In the current study, for the first time, we originally study linear and non-linear optical characteristics such as fluorescence emission, second harmonic generation and two photons emissions and also medicinal and pharmaceutical applications of Cadmium Oxide $(\mathrm{CdO})$ nanoparticles for eliminating cancer cells. In this regard, the effect of Cadmium Oxide (CdO) nanoparticles on DNA of human cancer cells and the interaction of Cadmium Oxide $(\mathrm{CdO})$ nanoparticles with DNA of cancer cells are investigated.

\section{Test method}

Non-doped Cadmium Oxide $(\mathrm{CdO})$ films were produced on glass substrate using 1 molar Cadmium acetate solution with distilled water and ethanol. The volume of solution is $65(\mathrm{ml})$ and the ratio of ethanol to water is 2:2. The temperature of solution was changed between 450 and $600{ }^{\circ} \mathrm{C}$. The obtained solution was sprayed with flow rate of 55 (lit/min). By reaching the close drops to the bottom of warm layer, pyrolytic process produces and Cadmium Oxide $(\mathrm{CdO})$ film with high adhesion occurs.

After completion of deposition process, the temperatures of films were reduced to the room temperature. The X-Ray Diffraction (XRD) spectrum of compounds is achieved by PANalytical-X'Pert Pro MPD with $\mathrm{Cr} \mathrm{K} \alpha$ rays in the angle range of $2 \theta=5^{\circ}-80^{\circ}$. The device is used to investigate structural characteristics of samples. ATR-FTIR spectrum in the range of 400-1000 nanometers is obtained by a ATR-FTIR Bruker Spectrophotometer. The spectrum shows optical characteristics of samples. Also, in the current research, grain sizes are calculated by X'Pert HighScore Plus software based on Scherrer equation.

Cadmium Oxide $(\mathrm{CdO})$ nanoparticles were produced by laser ablation of Cadmium plate (99.99\%) in distilled water. Before testing, Cadmium plate and beaker were washed and cleaned by alcohol, acetone and distilled water in ultrasonic device (ultrasonic bath). Then, Cadmium plate was placed in a beaker filled by $40(\mathrm{ml})$ distilled water and was subjected to laser with 9 (ns) pulse width and repeating rate of $15(\mathrm{~Hz})$ for 9 minutes. In this test, Nd:YAG laser with switch Q was used. In this state, laser emission with 3-3.5 (mm) diameter was focused using a lens with $95(\mathrm{~mm})$ focal distance. Cadmium Oxide $(\mathrm{CdO})$ nanoparticles were produced using Nd:YAG laser with 1256 (nm) wavelength and 2-3.5 (J) pulse energy and Nd:YAG laser with $784(\mathrm{~nm})$ wavelength (second harmonic) and 0.71 and $0.89(\mathrm{~J})$ pulse energy. Table 1 lists the details of prepared samples. Various detecting analyses were used to identify the characteristics of Cadmium Oxide 
$(\mathrm{CdO})$ nanoparticles. To evaluate the shape and size of the produced nanoparticles, Transmission Electron Microscope (TEM HD-2700) were used. In addition, size distribution of Cadmium Oxide (CdO) nanoparticles was measured by Dynamic Light Scattering (DLS) system Malvern Zetasizer with particle size range $0.3(\mathrm{~nm})$ to 10 $(\mu \mathrm{m})$, temperature range $90{ }^{\circ} \mathrm{C}$, size measurement of sizes $<1 \mathrm{~nm}$, size measurement of molecules with $\mathrm{MW}<1000 \mathrm{Da}$ and Low volume requirement (as little as $2(\mu \mathrm{L})$ ). Variations of electromagnetic absorption spectrum in the range of 400 to 1300 nanometers were measured by PG instruments Ltd spectrometer. The Varian Cary Eclipse Fluorescence Spectrophotometer, equipped with Xenon lamp, was used to evaluate characteristics of fluorescence.

Table ILaser wavelength and pulse energy for prepared samples

\begin{tabular}{lllllll}
\hline Laser Wavelength $(\mathbf{n m})$ & 784 & \multicolumn{1}{l}{ I 256 } \\
\hline Energy of Pulse (J) & $0.7 \mathrm{I}$ & 0.89 & 2 & 2.5 & 3 & 3.5 \\
Sample & $\mathrm{I}$ & 2 & 3 & 4 & 5 & 6 \\
\hline
\end{tabular}

\section{Analyses}

\section{Structural characteristics}

The structural characteristics of films are studied using X-Ray Diffraction (XRD). Figure 2 shows X-Ray Diffraction (XRD) of the produced films in various temperatures. The results obtained from X-Ray Diffraction (XRD) analysis shows that the produced films are polycrystalline and have a wurtzite structure. By increasing the temperature up to $500^{\circ} \mathrm{C}$, a better crystalline structure with a certain preferred direction is obtained. At higher temperatures, the crystalline structure collapses and the intensity of $(002)$ peak reduces. The crystallite size of Cadmium Oxide $(\mathrm{CdO})$ can be calculated by Scherrer equation.

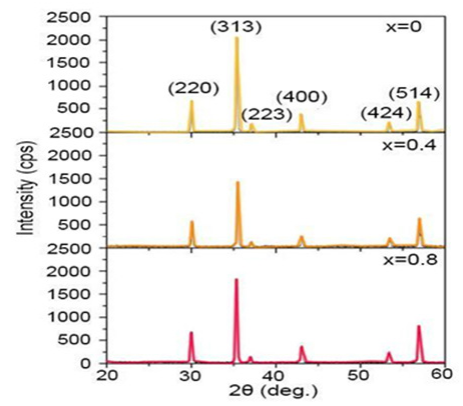

Figure 2 X-Ray Diffraction (XRD) of the produced films in various temperatures.

The variations of crystallite size as a function of substrate temperature is shown in Figure 3. Firstly, the crystallite size increases up to the maximum value of $63.7(\mathrm{~nm})$, at $500^{\circ} \mathrm{C}$, with increase in temperature of substrate and then decreases. Increase in crystallite size with increase in temperature may be due to improve in process of reaction between sprayed drops as well as improve in mobility of atoms in the surface of substrate.

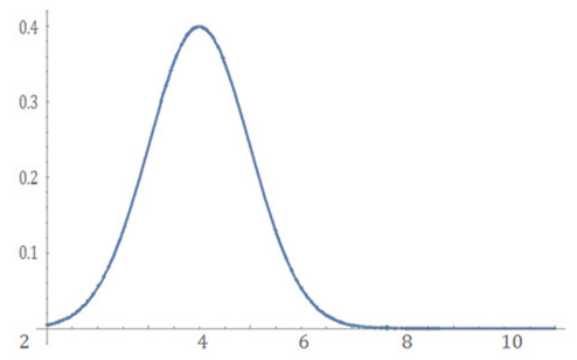

Figure 3 Variation of crystallite size against temperature.

\section{Optical characteristics}

Figure 4 shows the spectrum transmitted through Cadmium Oxide $(\mathrm{CdO})$ films in a region with wavelength ranged between $400-1000$ $(\mathrm{nm})$ at the temperature between $450-600^{\circ} \mathrm{C}$. Temperature variation is of a key role in transparency and optical characteristics of films. The diagrams obtained from spectrum transmitted through films are transparent in visible region and by increasing the temperature of substrates, transparency reduces. It can be concluded that increase in temperature makes devastating effects due to penetration of substrate compounds into films and hence, leads to reduce in transparency.

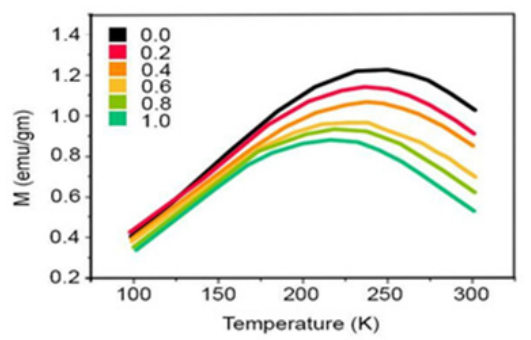

Figure 4 The spectrum transmitted through Cadmium Oxide (CdO) films produced at various temperatures.

\section{Optical, Medicinal and Pharmaceutical Characteristics of Cadmium Oxide (CdO) Nanoparticles}

Sample preparation: Cadmium Oxide $(\mathrm{CdO})$ nanoparticles used in the current study are produced by gas evaporation technique. As the goal of the current study is using Cadmium Oxide (CdO) in bioapplications, 0.1 (gr) of the nanoparticles are solved in 55 $(\mathrm{ml})$ of deionized water. All presented results are obtained in room temperature. Figure 1 is pointed out in abstract shows the results obtained from Scanning Electron Microscope (SEM) technique on Cadmium Oxide (CdO) nanoparticles with 50000x zoom. The size of these nanoparticles are about 250-400 nanometers.

Fluorescence: Fluorescence is a spontaneous emission induced by linear stimulation of photons. Fluorescence of semiconductors such as Cadmium Oxide (CdO) can be explained using energy levels. Using a photon with higher energy level than gap energy, it can be possible to stimulate electrons of conducting band and move them to conducting band and hence, only holes with positive charge remain on the valence band. This electron and hole is called exciton. Electrons on conducting band and before recombination can be non-optically transited (usually vibration transition type) between the available compressed levels in conducting band. In this state, the energy difference between electron and hole is lower than the initial state and hence, the produced photon from recombination of electron and hole is of longer wavelength than the initial stimulator photon. If the energy level of stimulator photon is higher than the gap energy of semiconductor, electron moves to higher levels of conducting band but if the energy level of photon is lower than the gap energy, there is no absorption and hence, there is no emission. The single photon fluorescence stimulation of these nanoparticles obtained from stimulation gap and 9 nanometers disclosure with wavelength of 430 and 470 nanometers are shown in Figure 5. As can be seen in this figure, the fluorescence emission of these nanoparticles has a peak in 380 nanometers wavelength $(4.4 \mathrm{eV})$ which is related to gap edge exciton transition.

The other peak, which is wider and is seen in green zone, is induced by surficial deficiencies such as impurities, Oxygen and or Cadmium vacuum. In these nanoparticles, such impurities and hence, the associated transitions were inevitable. However, the emissions induced by deficiencies are not always inappropriate; they can be used as efficient source of white light. 


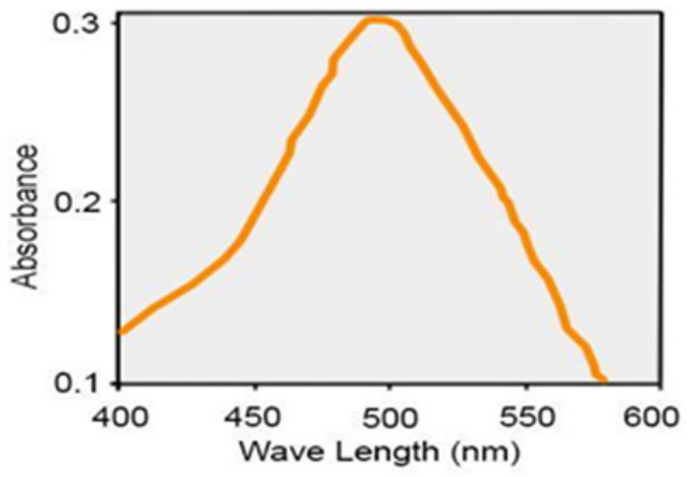

Figure 5 Fluorescence spectrum of Cadmium Oxide (CdO) nanoparticles.

\section{Second harmonic generation}

Since Cadmium Oxide ( $\mathrm{CdO})$ has a considerable non-linear coefficient, the other part of the current study is focused on investigating non-linear characteristics of Cadmium Oxide (CdO). High power pulse laser with high peak power should be used to observe non-linear characteristics. Tunable Titanium sapphire laser with pulselength of 185 femtoseconds was used to stimulate Cadmium Oxide (CdO) nanoparticles. Cadmium Oxide $(\mathrm{CdO})$ nanoparticles sample solved in water was subjected to NIR emission in quartz cell. Laser light was focused on quartz cell using a lens with focal distance of $22(\mathrm{~cm})$ and second harmonic was generated. To detect the second harmonic signal, two lenses with wide mount and with degree of 180 from descending light were used. Before entering signal to detector, a NIR filter was installed on the mount of camera to remove the descending laser light. Figure 6 shows the results of second harmonic stimulation of Cadmium Oxide ( $\mathrm{CdO}$ ) nanoparticles in photon counting state and in wavelengths of $800,825,850,875,900,925,950,975$ and 1000 $(\mathrm{nm})$. By distancing from 800 nanometers wavelength, laser power has a descending trend which causes to reduce in second harmonic peaks of these nanoparticles. Figure 6 shows normalized results.
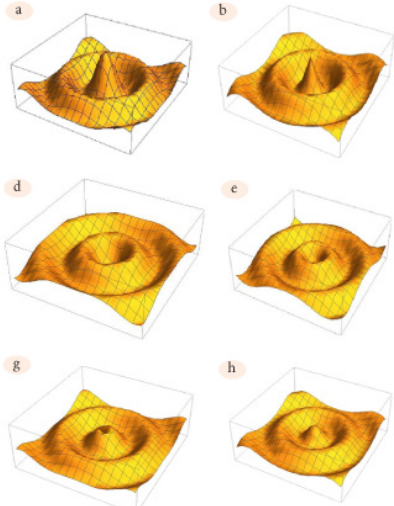

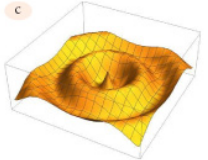

f

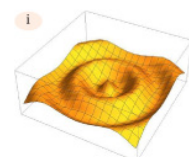

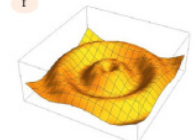

Figure 6 Second harmonic spectrum of Cadmium Oxide (CdO) nanoparticles with various stimulated wavelength: (a) 800 (nm); (b) 825 (nm); (c) 850 (nm); (d) 875 (nm); (e) 900 (nm); (f) 925 (nm); (g) 950 (nm); (h) 975 (nm); (i) 1000 (nm).

\section{Two photons absorption}

When Cadmium Oxide (CdO) nanoparticles stimulate with a wavelength that the energy of descending photon (ex) satisfies $4 \mathrm{ex}>\mathrm{Eg}$ and there is a considerable two photons absorption cross section, two photons absorption occurs. Therefore, if Cadmium Oxide (CdO) nanoparticles stimulate with wavelength ranged between 900 950 nanometers, two photons emissions occurs. In a narrow range (950-1000 nanometers), two photons absorption occurs in addition to second harmonic generation, simultaneously. Figure 7 shows this state for 4 different wavelengths schematically.

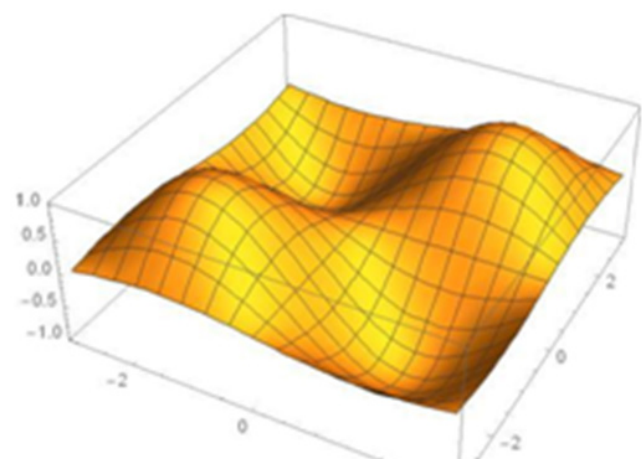

Figure 7 Simultaneous spectrums of two photons emission and second harmonic generation.

As can be seen, emission induced by two photons absorption is wider than second harmonic generation. In this narrow zone, shorter wavelength means that the contribution of two photons absorption is higher and by increasing wavelength, two photons emissions disappears. In Figure 7, Cadmium Oxide $(\mathrm{CdO})$ nanoparticles are stimulated by wavelength between 900 and 930 nanometers and second harmonic generation and two photons emission are simultaneously appeared (in this case, arrangement is similar to second harmonic detection in counting photon case).

\section{Applications of Cadmium Oxide (CdO) nanoparticles in medicine and pharmaceutics}

Currently, nano-atto second pulse lasers are used to image from biosamples. Such systems are of very high power peak which is higher than the failure threshold of biosamples. However, average power of lasers is important for non-linear imaging of biosamples. It may be possible that pulse lasers have average power less than $1.5(\mathrm{~W})$ and peak power more than $1.5(\mathrm{GW})$. Since relaxation time between pulses are adequate (repeat rate of about $105 \mathrm{MHz}$ ), the average power of laser is lower than failure threshold of biosamples while their peak power is of required capability to non-linearly stimulate samples.

Second harmonic generation is only a frequency conversion process and no absorption occurs in this process, so it can be used to image from bioamples. Cadmium Oxide $(\mathrm{CdO})$ is able to pass through cell wall and enters into the cell. In this manner, non-linear characteristics of Cadmium Oxide $(\mathrm{CdO})$ nanoparticles were used for imaging and tracing of animal cells.

The current investigation shows that second harmonic signal of these nanoparticles can be used for stable and longtime imaging and tracing. Since two photons absorption is of more penetration depth and is accompanied by heat production, two photons imaging was always accompanied by heat and sample burning and can be used to eliminate cancer cells.

\section{Results and discussion}

Figure 8 shows absorption spectrum of Cadmium Oxide (CdO) nanoparticles considering the absorption of distilled water as reference. 


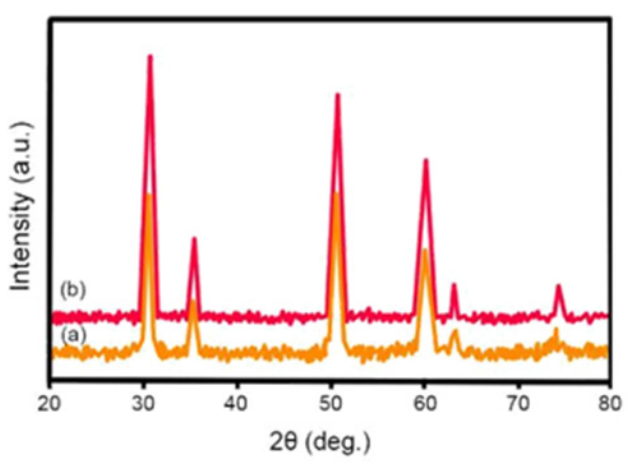

Figure 8 Absorption spectrum of Cadmium Oxide (CdO) nanoparticles in distilled water produced at (a) 784 nanometers wavelength, (b) 1046 nanometers wavelength.

The peak of UV absorption resulted from absorption of Cadmium Oxide $(\mathrm{CdO})$ nanoparticles exciton is happened at 322-363 nanometers wavelength. The effect of size of nanoparticles on electronic structure of semiconductors explains by increase in band gap with decrease in size of particles which attributed to quantum surrounding effect. A blue shift in the edge of absorption was observed with increase in laser pulse energy which can be used to qualitatively describe the size distribution of particles. In smaller nanoparticles (in higher laser energies), a sharp peak of exciton is presented in the absorption spectrum which shows limited size distribution of nanoparticles in the sample and for larger particles, this is not observed in absorption spectrum (in lower laser energies). The reason is the fact that a number of exciton peaks in various energies are related to nanoparticles with various sizes which overlaps each other. Therefore, it can be expected that size distribution of nanoparticles extends. This assumption is confirmed using size distribution of nanoparticles resulted from Dynamic Light Scattering (DLS) analysis in various samples (Figure 9).
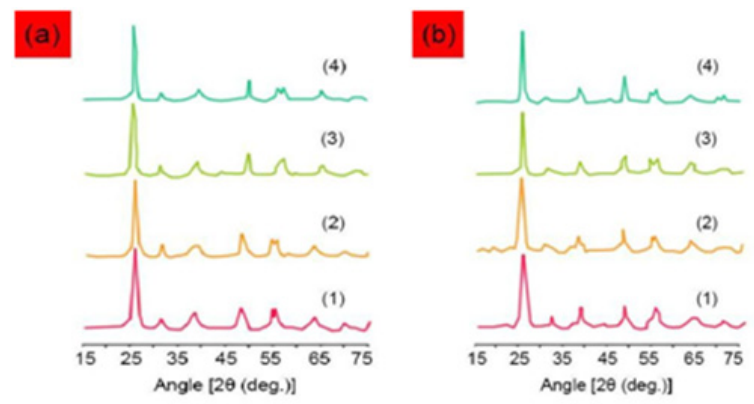

Figure 9 Size distribution of nanoparticles resulted from Dynamic Light Scattering (DLS) analysis (I) sample 3, (2) sample 4, (3) sample 5 and (4) sample 6.

As can be seen in Figure 9, size of nanoparticles is decreased with increase in laser pulse energy. The average size of nanoparticles is listed in Table 2.

Table 2 Size of Cadmium Oxide (CdO) nanoparticles

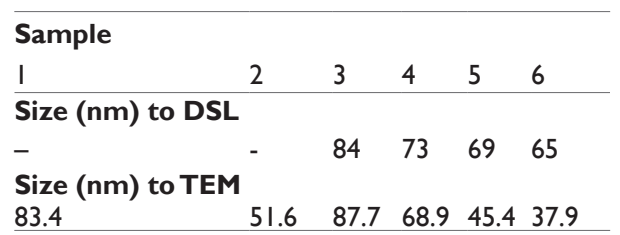

Considering the fact that Dynamic Light Scattering (DLS) analysis shows hydrodynamic size of particles, the results of this analysis is considerably higher than those resulted from Transmission Electron Microscope (TEM) images. It may be due to the forming of Hydrogen bond between carboxyl group on the next surface, which can lead to transversal connection between particles and hence, larger particles. Transmission Electron Microscope (TEM) images of Cadmium Oxide (CdO) nanoparticles, which are in the scale of about 250 nanometers, are shown in Figure 10. As can be seen, nanoparticles are approximately spherical and their sizes are reduced by increase in laser pulse energy.

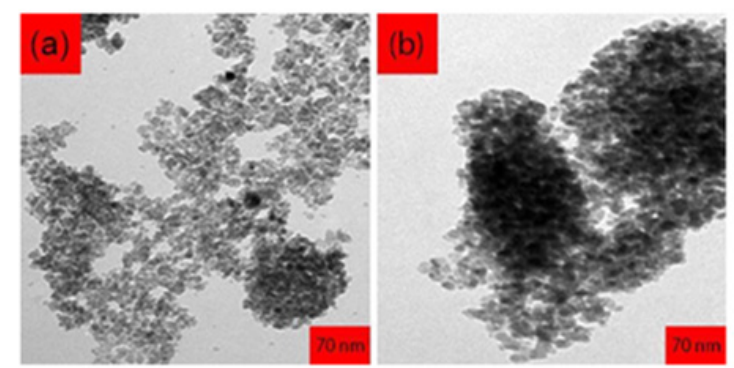

Figure 10 Transmission Electron Microscope (TEM) images of Cadmium Oxide (CdO) nanoparticles with 35000x zoom.

Variations of size distribution of nanoparticles by increase in laser pulse energy are similar to the results obtained from Dynamic Light Scattering (DLS) analysis. In other words, size distribution of nanoparticles is uniform. By increasing the laser pulse energy, larger nanoparticles can be simply broken into smaller parts due to interaction with intense laser pulse.

Figure 11 shows the fluorescence spectrum of Cadmium Oxide (CdO) nanoparticles which are stimulated by Xenon lamp in wavelength of 407 nanometers. Usually, emission band in UV and visible fields are observed in fluorescence spectrum of Cadmium Oxide (CdO) nanoparticles. UV peak, which is usually considered as an indication of Cadmium Oxide ( $\mathrm{CdO})$ emission, is called edge band emission or exciton transmission. However, emission bands in visible zone are induced by recombination of holes resulted from photon emission with charged, ionized state in inherent deficiencies such as Oxygen blank space, inter-lattice $\mathrm{Cd}$ and or impurities. First of all, if stimulation energy is considered considerably lower than gap energy and the second, if the intensity of visible light emission induced by increase in density of deficiencies is very high. In all samples of Cadmium Oxide $(\mathrm{CdO})$ nanoparticles, the peak of UV in fluorescence spectrum is dominant and its intensity increases with increase in laser pulse energy while the intensity of the presented peaks in visible zone is decreased. In other words, severe exciton emission shows that the produced Cadmium Oxide $(\mathrm{CdO})$ nanoparticles are of little deficiencies.

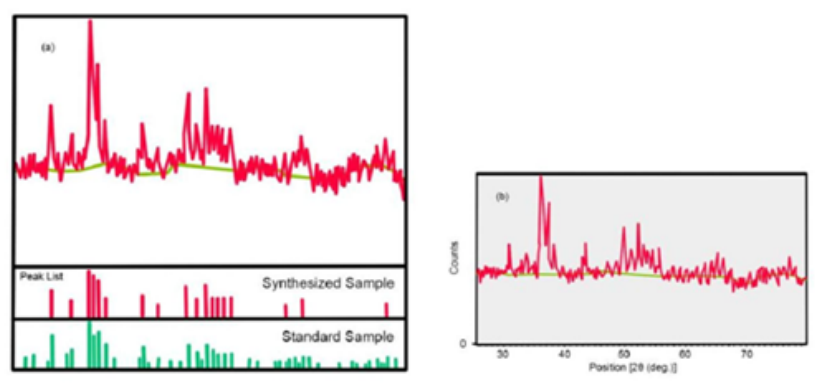

Figure I I Fluorescence spectrum of Cadmium Oxide (CdO) nanoparticles produced at (a) 784 nanometers wavelength, (b) 1256 nanometers wavelength.

General outline of energy level graph of Cadmium Oxide (CdO) nanoparticles is shown in Figure 12. Various deficiencies are 
considered in this model. The first principle shows that $\mathrm{Cd}_{3 \mathrm{~d}}$ electron is severely interacted with $\mathrm{O}_{2 p}$ electron of Cadmium Oxide (CdO). As can be seen in Figure 12, fluorescence in violet zone can be attributed to transmission from conducting band to deep holes tra pped in a level such as $\mathrm{V}_{\mathrm{Cd}}$. Blue emission can be considered as direct recombination of conducting electron in $\mathrm{Cd}_{3 \mathrm{~d}}$ band and hole in $\mathrm{O}_{2 \mathrm{p}}$ valence band. The usual process for green emission is as following: transmission mechanism (a) from proximity of conducting band edge to deep level of receptor and (b) from deep level of donor to valence band. Recombination of surficial electron trapped in a deep hole trapped in center of $\mathrm{V}_{0}++$ leads to visible emission.

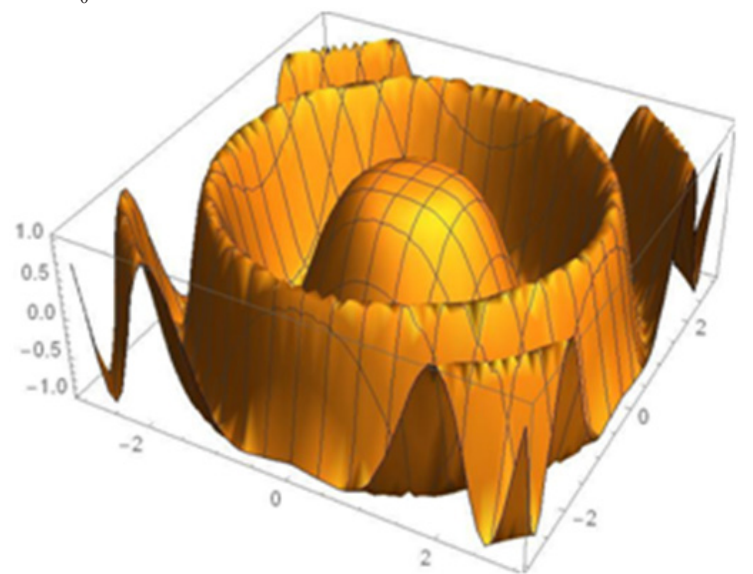

Figure 12 General outline of energy level graph of Cadmium Oxide (CdO) nanoparticles.

It should be noted that the effect of Cadmium Oxide (CdO) nanoparticles on DNA of human cancer cells is listed in Table 3. In addition, Figures $13 \& 14$ demonstrate fluorescence and photoluminescence of Cadmium Oxide $(\mathrm{CdO})$ nanoparticles in violet zone (a) from proximity of conducting band edge to deep level of receptor and (b) from deep level of donor to valence band, respectively. Moreover, as can be seen, Figures $15 \& 16$ display intensity dependence of fluorescence and photoluminescence of Cadmium Oxide $(\mathrm{CdO})$ nanoparticles in different wavelengths. Furthermore, Scanning Electron Microscope (SEM) images and also Transmission Electron Microscope (TEM) images of Cadmium Oxide (CdO) nanoparticles (a) before interaction with DNA of cancer cells and (b) after interaction with DNA of cancer cells is shown in Figures $17 \& 18$, respectively. Also, as another novel achievement, simulation of Cadmium Oxide (CdO) nanoparticles before and after interaction with DNA of cancer cells is illustrated in Figure 19.

Table 3 Effect of Cadmium Oxide (CdO) nanoparticles on DNA of human cancer cells

\begin{tabular}{lll}
\hline Concentrations & $\begin{array}{l}\text { DNA of Human Cancer DNA of Human Cancer } \\
\text { Cells (ppm) before } \\
\text { Interaction with CdO }\end{array}$ & $\begin{array}{l}\text { Cells (ppm) after } \\
\text { Interaction with CdO }\end{array}$ \\
\hline Control & $1.84 \pm 0.23$ & $7 \pm 0.63$ \\
$0.001 \mu \mathrm{g} / \mathrm{ml} \mathrm{CdO}$ & $17.34 \pm 0.73$ & $1.94 \pm 0.01$ \\
$0.003 \mu \mathrm{g} / \mathrm{ml} \mathrm{CdO}$ & $1.67 \pm 0.42$ & $0.01 \pm 0.000 \mathrm{I}$ \\
$0.005 \mu \mathrm{g} / \mathrm{ml} \mathrm{CdO}$ & $1.73 \pm 0.19$ & $0.01 \pm 0.000 \mathrm{I}$ \\
$0.007 \mu \mathrm{g} / \mathrm{ml} \mathrm{CdO}$ & $1.94 \pm 0.54$ & $0.01 \pm 0.000 \mathrm{I}$ \\
$0.07 \mu \mathrm{g} / \mathrm{ml} \mathrm{CdO}$ & $2.28 \pm 0.1 \mathrm{I}$ & $0.01 \pm 0.000 \mathrm{I}$ \\
$0.7 \mu \mathrm{g} / \mathrm{ml} \mathrm{CdO}$ & $2.73 \pm 0.8 \mathrm{I}$ & $0.01 \pm 0.0001$ \\
\hline
\end{tabular}
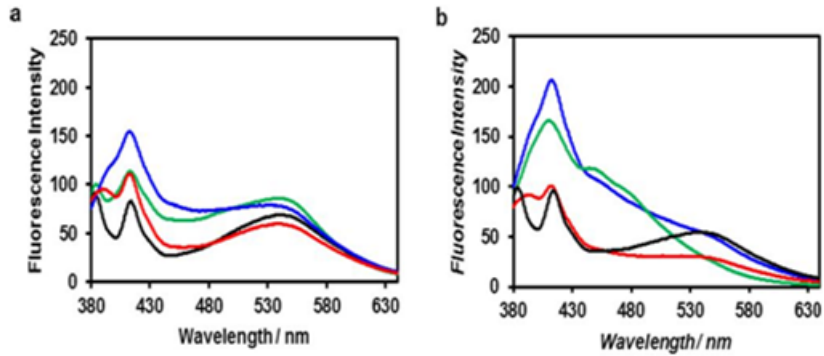

Figure 13 Fluorescence of Cadmium Oxide (CdO) nanoparticles in violet zone (a) from proximity of conducting band edge to deep level of receptor, (b) from deep level of donor to valence band.
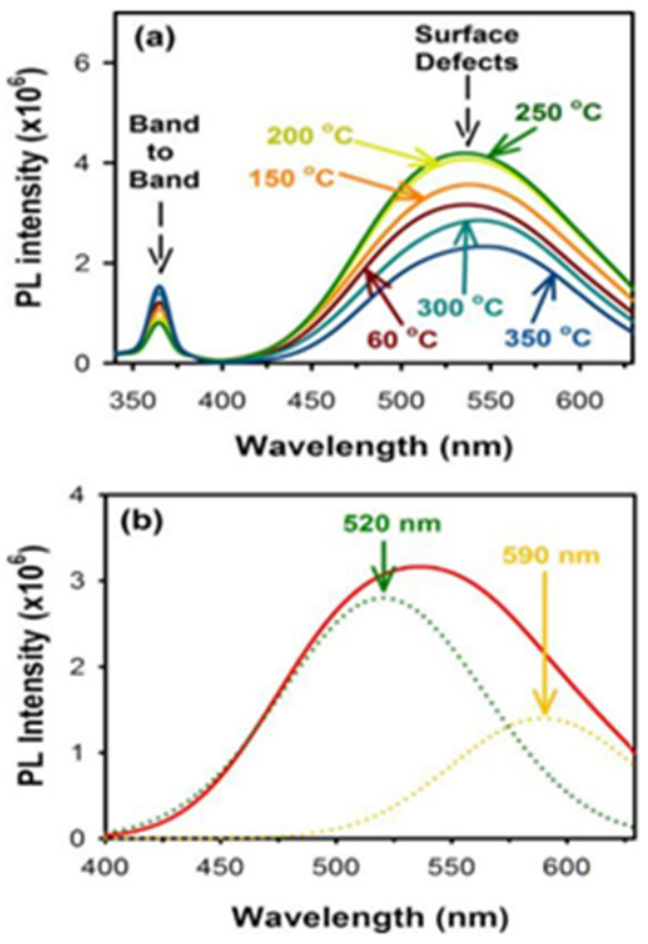

Figure 14 Photoluminescence of Cadmium Oxide (CdO) nanoparticles in violet zone (a) from proximity of conducting band edge to deep level of receptor, (b) from deep level of donor to valence band.

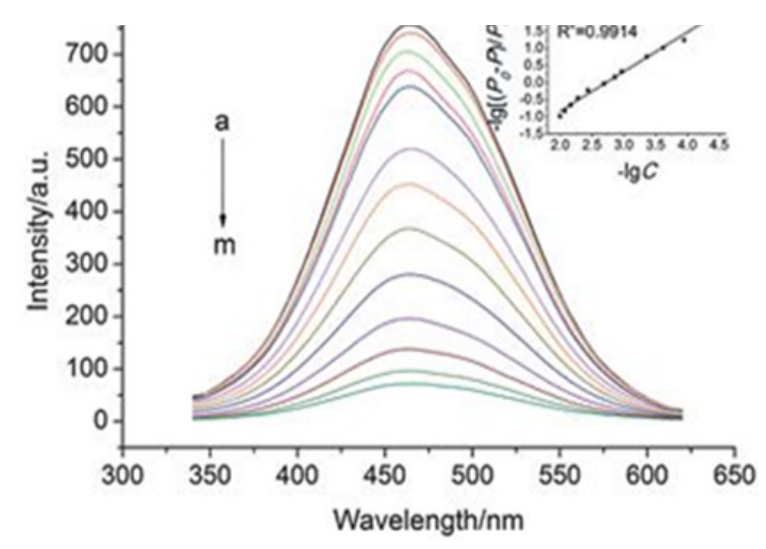

Figure 15 Intensity dependence of fluorescence of Cadmium Oxide (CdO) nanoparticles in different wavelengths. 

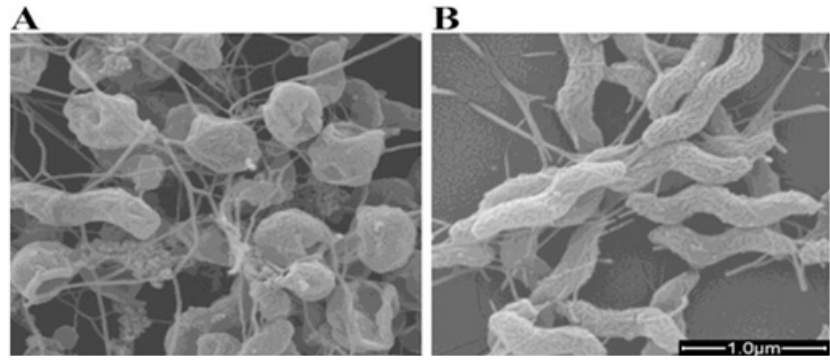

Figure 17 Intensity dependence of photoluminescence of Cadmium Oxide (CdO) nanoparticles in different wavelengths.

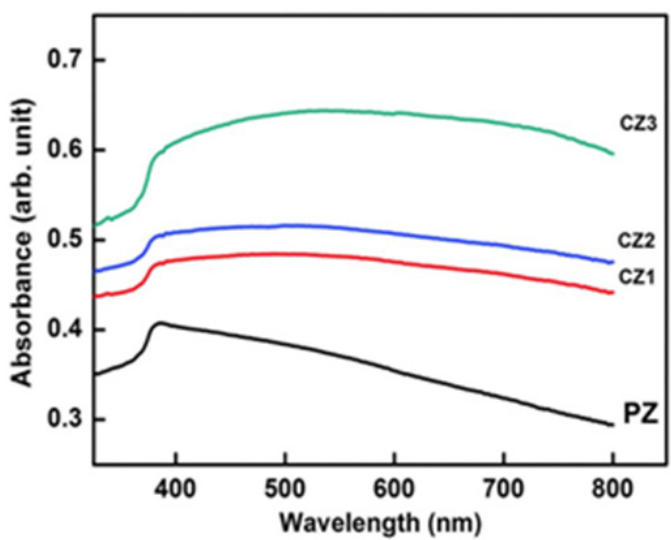

Figure 16 Intensity dependence of photoluminescence of Cadmium Oxide (CdO) nanoparticles in different wavelengths.
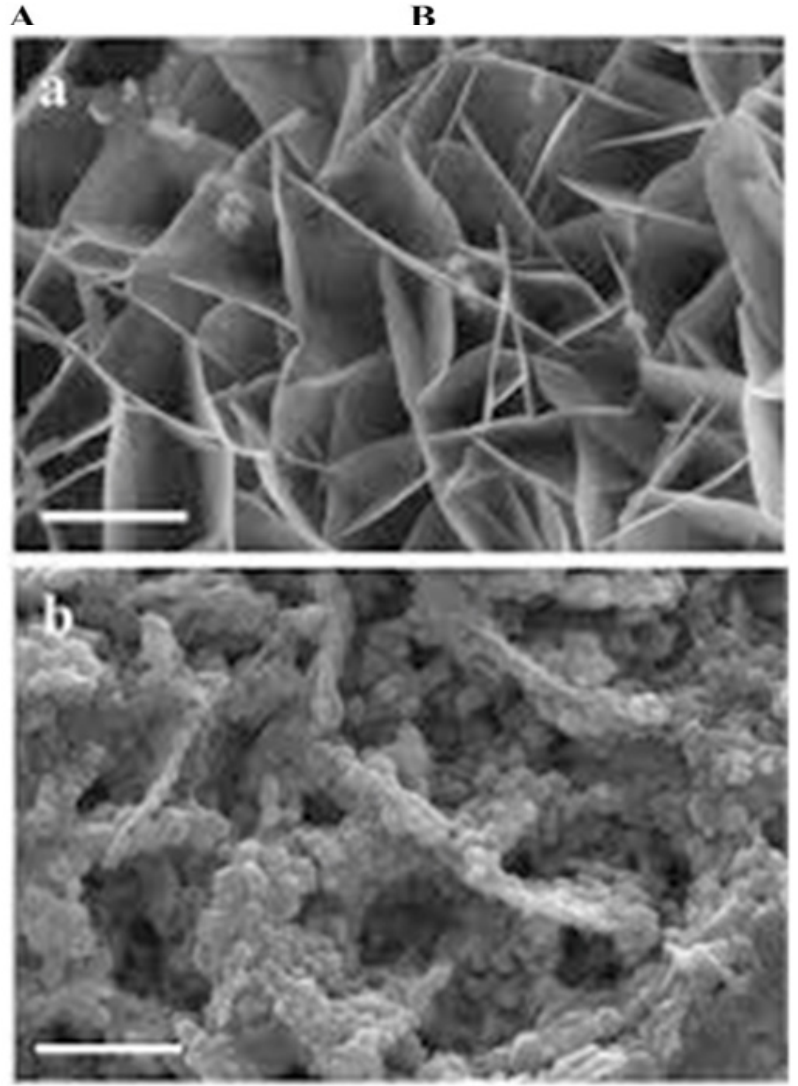

Figure 18 Transmission Electron Microscope (TEM) images of Cadmium Oxide (CdO) nanoparticles with 55000x zoom (a) before interaction with DNA of cancer cells, (b) after interaction with DNA of cancer cells.
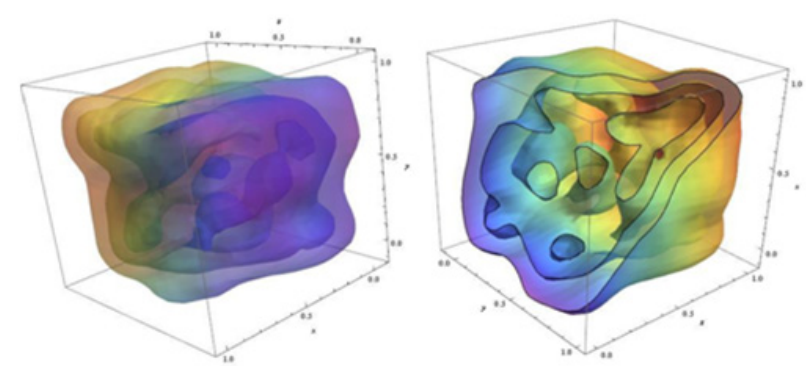

Figure 19 Simulation of Cadmium Oxide (CdO) nanoparticles before (left illustration) and after (right illustration) interaction with DNA of cancer cells.

\section{Conclusion}

Cadmium Oxide (CdO) films were successfully deposited using Spray Pyrolysis Technique at various temperatures ranged between $450-600^{\circ} \mathrm{C}$. The maximum preferred peak (002) is at $500^{\circ} \mathrm{C}$. According to $\mathrm{X}$-Ray Diffraction (XRD) study, it is clear that the size of crystallite increases as the temperature increases up to $500^{\circ} \mathrm{C}$ and hence, absorption increases by increase in size of crystallite and therefore, optical transmittance decreases. At higher temperatures, penetration of substrate compounds into films leads to reduce in transparency.

In the current test, Cadmium Oxide $(\mathrm{CdO})$ nanoparticles were produced by laser ablation of Cadmium plate in distilled water. The obtained results shown that tasting parameters such as laser pulse energy and wavelength are effective on characteristics of Cadmium Oxide $(\mathrm{CdO})$ nanoparticles such as effective size of nanoparticles. Therefore, to optimize and produce nanoparticles with especial characteristics, parameters of laser ablation can be controlled. The obtained results from Transmission Electron Microscope (TEM) and Dynamic Light Scattering (DLS) analyses showed that size of Cadmium Oxide $(\mathrm{CdO})$ nanoparticles decreases by increasing laser pulse energy. The presence of severe exciton emission in fluorescence spectrum indicates that by increasing laser pulse energy, Cadmium Oxide $(\mathrm{CdO})$ nanoparticles with lower deficiencies are produced.

In the current study, linear and non-linear optical characteristics of Cadmium Oxide $(\mathrm{CdO})$ nanoparticles and their applications as a reliable and harmless label, which has not problems of colors and quantum dots and can be used with high stability in non-linear imaging, was explained. Cadmium Oxide $(\mathrm{CdO})$ nanoparticles are of high second harmonic with high resolution which can be used for imaging with microscope without any failure of sample.

\section{References}

1. Thovhogi N, Park E, Manikandan E et al. Physical properties of CdO nanoparticles synthesized by green chemistry via Hibiscus Sabdariffa flower extract. Journal of Alloys and Compounds. 2016;655:314-320.

2. Thema FT, Beukes P, Gurib-FakimA et al. Green synthesis of Monteponite $\mathrm{CdO}$ nanoparticles by Agathosma betulina natural extract. Journal of Alloys and Compounds. 2015;646:1043-1048.

3. Naif Mohammed Al-Hada, Elias BS, Abdul HS, Mazliana AK et al. A facile thermal-treatment route to synthesize the semiconductor $\mathrm{CdO}$ nanoparticles and effect of calcinations. Materials Science in Semiconductor Processing. 2014;26:460-466.

4. Sivakumar S, Venkatesan A, Soundhirarajan P et al. Thermal, structural, functional, optical and magnetic studies of pure and $\mathrm{Ba}$ doped CdO nanoparticles. Spectrochim Acta A Mol Biomol Spectrosc. 2015;151:760-772. 
5. Della Torre C, Balbi T, Grassi G et al. Titanium dioxide nanoparticles modulate the toxicological response to cadmium in the gills of Mytilus galloprovincialis. J Hazard Mater. 2015;297:92-100.

6. Karsten Klauke, Björn Hahn, Kai Schütte et al. Bis((dialkylamino) alkylselenolato)metal complexes as precursors for microwave-assisted synthesis of semiconductor metal selenide nanoparticles of zinc and cadmium in the ionic liquid [BMIm][ BF4]. Nano-Structures \& NanoObjects. 2015;1:24-31.

7. Sabriye Acikgoz, Yakup Ulusu, Seckin Akin et al. Photoinduced electron transfer mechanism between green fluorescent protein molecules and metal oxide nanoparticles. Ceramics International. 2014;40(2): 2943-2951.

8. Jiménez-Pérez JL, Gutiérrez FR, Sánchez-Sosa R et al. Thermal diffusivity study of nanoparticles and nanorods of titanium dioxide (TiO2) and titanium dioxide coated with cadmium sulfide ( $\mathrm{TiO} 2 \mathrm{CdS}$ ). Materials Science in Semiconductor Processing. 2015;37:62-67.

9. Sivakumar S, Venkatesan A, Soundhirarajan P et al. Synthesis, characterizations and anti-bacterial activities of pure and Ag doped $\mathrm{CdO}$ nanoparticles by chemical precipitation method. Spectrochim Acta A Mol Biomol Spectrosc. 2015;136:1751-1759.

10. Mi Jung Choi, Andrew M McDonagh, Philip Maynard et al. Metalcontaining nanoparticles and nano-structured particles in fingermark detection. Forensic Science International. 2008;179(2-3):87-97.

11. Gong J, Chen L, Zeng G et al. Shellac-coated iron oxide nanoparticles for removal of cadmium(II) ions from aqueous solution. J Environ Sci. 2012;24(7):1165-1173.

12. Nutthaya B, Lin Z, Wittaya $\mathrm{N}$ et al. A sensitive nonenzymatic hydrogen peroxide sensor using cadmium oxide nanoparticles/multiwall carbon nanotube modified glassy carbon electrode. Journal of Electroanalytical Chemistry. 2014;717-718:41-46.

13. Vidyasagar CC, Arthoba Naik Y, Venkatesh TG et al. Solidstate synthesis and effect of temperature on optical properties of $\mathrm{Cu}-\mathrm{ZnO}, \mathrm{Cu}-\mathrm{CdO}$ and $\mathrm{CuO}$ nanoparticles. Powder Technology. 2011;214(3):337-343.

14. Di Zhang, Yanyan Chen, Haijun Pang et al. Enhanced electrochromic performance of a vanadium-substituted tungstophosphate based on composite film by incorporation of cadmium sulfide nanoparticles. Electrochimica Acta. 2013;105:560-568.

15. Aytaç Gültekin, Gamze Karanfil, Faruk et al. Synthesis and characterisations of $\mathrm{Au}$-nanoparticle-doped $\mathrm{TiO} 2$ and $\mathrm{CdO}$ thin films. Journal of Physics and Chemistry of Solids. 2014 ;75(6):775-781.

16. Kenji Iwahori, Midori Yamane, Sakiko Fujita et al. Synthesizing CdSe nanoparticles by using a low concentration of cadmium ions and the apoferritin protein cage of marine pennate diatoms. Materials Letters. 2015;160:154-157.

17. Jianyu Xin, Ping Dong, Lu Pu et al. Cadmium sulfide nanoparticles with controllable morphology, photoluminescence and photocatalytic activity templated by worm-like dendronized poly(amido amine)s. Colloids and Surfaces A: Physicochemical and Engineering Aspects. 2014;450:25-35.

18. Zhiping Yan, Haotian Wu, Ali Han et al. Noble metal-free cobalt oxide (CoOx) nanoparticles loaded on titanium dioxide/ cadmium sulfide composite for enhanced photocatalytic hydrogen production from water. International Journal of Hydrogen Energy. 2014;39(25):13353-13360.

19. Rakesh KS, Amey Wadawale, Kedarnath G et al. Pyrimidyl-2selenolates of cadmium and mercury: Synthesis, characterization, structures and their conversion to metal selenide nano-particles. Inorganica Chimica Acta. 2014;411:90-96.

20. Zhaomeng Wang, Lin Li, Erjia Liu Graphene ultrathin film electrodes modified with bismuth nanoparticles and polyaniline porous layers for detection of lead and cadmium ions in acetate buffer solutions. Thin

\section{Solid Films. 2013;544:362-367.}

21. Sheela T, Arthoba Nayaka Y Kinetics and thermodynamics of cadmium and lead ions adsorption on $\mathrm{NiO}$ nanoparticles. Chemical Engineering Journal. 2012;191:123-131.

22. Wang M, Chen L, Chen S, Ma Y Alleviation of cadmium-induced root growth inhibition in crop seedlings by nanoparticles. Ecotoxicol Environ Saf. 2012;79:48-54.

23. Gupta VK, Arunima Nayak Cadmium removal and recovery from aqueous solutions by novel adsorbents prepared from orange peel and Fe2O3 nanoparticles. Chemical Engineering Journal. 2012;180:81-90.

24. Song Q, Li M, Huang L et al. Bifunctional polydopamine@Fe3O4 core-shell nanoparticles for electrochemical determination of lead(II) and cadmium(II). Anal Chim Acta. 2013;787:64-70.

25. Chávez Urbiola IR, Ramírez Bon R, Vorobiev YV The transformation to cadmium oxide through annealing of cadmium oxide hydroxide deposited by ammonia-free SILAR method and the photocatalytic properties. Thin Solid Films. 2015;592:110-117.

26. Ismail W, Muneer A, Naveen S et al. Synthesis, spectral, electrochemical, crystal structure studies of two novel di- $\mu-$ halo-bis[halo(2,9-dimethyl-4,7-diphenyl-1,10-phenanthroline) cadmium(II)] dimer complexes and their thermolysis to nanometal oxides. Journal of Molecular Structure. 2015;1099:323-329.

27. Hossain ST, Mukherjee SK Toxicity of cadmium sulfide (CdS) nanoparticles against Escherichia coli and HeLa cells. J Hazard Mater. 2013;260:1073-1082.

28. Chowdhury SR, Yanful EK Kinetics of cadmium(II) uptake by mixed maghemite-magnetite nanoparticles. J Environ Manage. 2013;129:642-651.

29. Khaled H Mahmoud, Zeinhom M El-Bahy, Ahmed I Hanafy Photoluminescence analysis of Er nanoparticles in cadmium-phosphate glasses. Journal of Non-Crystalline Solids. 2013;363:116-120.

30. Rakesh KS, Kedarnath G, Amey Wadawale et al. Monomeric pyridyl-2-selenolate complexes of cadmium and mercury: Synthesis, characterization and their conversion to metal selenide nanoparticles. Inorganica Chimica Act. 2011;365(1):333-339.

31. Aso Navaee, Abdollah Salimi N-hydroxysuccinimide--mediated photoelectrooxidation of aliphatic alcohols based on cadmium telluride nanoparticles decorated graphene nanosheet. Electrochimica Acta. 2013;105:230-238.

32. Kristl M, Ban I, Danc A et al. A sonochemical method for the preparation of cadmium sulfide and cadmium selenide nanoparticles in aqueous solutions. Ultrason Sonochem. 2010;17(5):916-922.

33. Nasser AM Barakat, Mohammad AA, Hak Yong K Ethanol electrooxidation using cadmium-doped cobalt/carbon nanoparticles as novel non precious electrocatalyst. Applied Catalysis A: General. 2013;455:193-198.

34. Ravi Kant U, Meenakshi S, Deepesh KS et al. Photo degradation of synthetic dyes using cadmium sulfide nanoparticles synthesized in the presence of different capping agents. Separation and Purification Technology. 2012;88: 39-45.

35. Swarup Maji K, Amit Kumar D, Divesh NS et al. Peroxidase-like behavior, amperometric biosensing of hydrogen peroxide and photocatalytic activity by cadmium sulfide nanoparticles. Journal of Molecular Catalysis A: Chemical. 2012;358:1-9.

36. Maseko NN, Revaprasadu N, Rajasekhar Pullabhotla VSR et al. The influence of the cadmium source on the shape of CdSe nanoparticles. Materials Letters. 2010;64(9):1037-1040.

37. Beverly AR, Jeannine SS Cadmium-containing nanoparticles: Perspectives on pharmacology and toxicology of quantum dots. Toxicology and Applied Pharmacology. 2009;238(3):280-288. 
38. Arslan Z, Ates M, McDuffy W et al. Probing metabolic stability of CdSe nanoparticles: Alkaline extraction of free cadmium from liver and kidney samples of rats exposed to CdSe nanoparticles. J Hazard Mater. 2011;192(1):192-199.

39. Tang JH, Xie L, Zhang B et al. Preparation of strongly fluorescent silica nanoparticles of polyelectrolyte-protected cadmium telluride quantum dots and their application to cell toxicity and imaging. Anal Chim Acta. 2012;720:112-117.

40. Viswanathan K, Bor FC Synthesis and characterization of poly(Nvinylpyrrolidine)-silica hybrid shell coated cadmium selenide / cadmium sulphide and cadmium selenide / zinc sulfide nanoparticles. Materials Letters. 2011;65(4):646-649.

41. Colorado HA, Dhage SR, Hahn HT Thermo chemical stability of cadmium sulfide nanoparticles under intense pulsed light irradiation and high temperatures. Materials Science and Engineering: $B$. 2011;176(15):1161-1168

42. Huang Y, Keller AA EDTA functionalized magnetic nanoparticle sorbents for cadmium and lead contaminated water treatment. Water Res. 2015;80:159-168.

43. Thiago LR, Tânia G, José PP et al. Toxicokinetics and tissue distribution of cadmium-based Quantum Dots in the marine mussel Mytilus galloprovincialis. Environmental Pollution. 2015;204:207-214.

44. Bishweshwar P, Hem Raj P, Nasser Barakat AM et al. Incorporation of cadmium sulfide nanoparticles on the cadmium titanate nanofibers for enhanced organic dye degradation and hydrogen release. Ceramics International. 2014;40(1):1553-1559.

45. Kedarnath G, Sandip D, Vimal KJ et al. 2-(N,N-Dimethylamino) ethylselenolates of cadmium(II): Syntheses, structure of [Cd3(OAc)2(SeCH2CH2NMe2)4] and their use as single source precursors for the preparation of CdSe nanoparticles. Polyhedron. 2006;25(12):2383-2391.

46. Thandeka M, Rajasekhar Pullabhotla VSR, Phumlani SM et al Synthesis of hexadecylamine capped CdS nanoparticles using heterocyclic cadmium dithiocarbamates as single source precursors. Polyhedron. 2009;28(14):2977-2982.

47. Thornton JM, Raftery D Hydrogen evolution by templated cadmium in date nanoparticles under natural sunlight illumination. International Journal of Hydrogen Energy. 2013;38(19):7741-7749.

48. Zhiqiang Y, Sreeram C, Kenneth JK An unusual fluorescence evolution of cadmium selenide (CdSe) nanoparticles generated from a cadmium oxide/trioctylphosphine selenide/trioctylphosphine heterogeneous system. Chemical Physics Letters. 2009;470(1-3):112-115.

49. Sayed AM El, Ali Ibrahim Structural and optical characterizations of spin coated cobalt-doped cadmium oxide nanostructured thin films. Materials Science in Semiconductor Processing. 2014;26:320-328.

50. Coccini T, Roda E, Barni S et al. Long-lasting oxidative pulmonary insult in rat after intratracheal instillation of silica nanoparticles doped with cadmium. Toxicology. 2012;302(2-3):203-211.

51. Wu S, Kaisheng Z, Xuelong W et al. Enhanced adsorption of cadmium ions by $3 \mathrm{D}$ sulfonated reduced graphene oxide. Chemical Engineering Journal. 2015;262:1292-1302.

52. Jia Y, Jing Li, Xuyu Y et al. A facile approach to anchor cadmium sulfide nanoparticles on graphene nanosheets as promising electrode materials. Materials Chemistry and Physics. 2012;135(2-3):687-693.

53. Jinkui F, Shenglin X, Yitai Q et al. Synthesis of nanosized cadmium oxide $(\mathrm{CdO})$ as a novel high capacity anode material for Lithium-ion batteries: influence of carbon nanotubes decoration and binder choice. Electrochimica Acta. 2014;129:107-112.

54. Braga A, Baratto C, Bontempi E, Colombi P et al. Transparent front contact optimization in dye sensitized solar cells: use of cadmium stannate and titanium oxide by sputtering. Thin Solid Films. 2014;555:18-20.

55. Manpreet Kaur, Shweta Rana, Tarsikka PS. Comparative analysis of cadmium doped magnesium ferrite $\mathrm{Mg}(1-\mathrm{x}) \mathrm{Cdx} \mathrm{Fe} 2 \mathrm{O} 4$ ( $\mathrm{x}=0.0,0.2$, 0.4, 0.6) nanoparticles. Ceramics International. 2012;38(5):4319-4323.

56. Narendra Singh, Shobhit Charan, Patil KR, et al. Unusual formation of nano-particles of $\mathrm{CdO}$ and $\mathrm{Cd}(\mathrm{OH}) 2$ from the reaction of dimethyl cadmium with DMF. Materials Letters. 2006;60(29-30):3492-3498.

57. Sheo KM, Rajneesh KS, Prakash SG, et al. Structural, optical and photoconductivity characteristics of manganese doped cadmium sulfide nanoparticles synthesized by co-precipitation method. Journal of Alloys and Compounds. 2012;513:118-124.

58. Ziyauddin Khan, Dipankar Barpuzary, Oruganti Baswant, et al. Directed growth of $1 \mathrm{D}$ cadmium sulfide by chemically anchored A12O3 and ZnO nanoparticles. Materials Letters. 2011;65(8):1168-1171.

59. Michael Wark, Henri Kessler, Günter Schulz-Ekloff. Growth and reactivity of zinc and cadmium oxide nano-particles in zeolites. Microporous Materials. 1997;8(5-6):241-253.

60. Punarja Kevin, Yousef G Alghamdi, et al. Morphology and band gap controlled AACVD of CdSe and CdSxSe1-x thin films using novel single source precursors: Bis(diethyldithio/diselenocarbamato) cadmium(II). Materials Science in Semiconductor Processing. 2015;40:848-854.

61. Yu-Long Xie, Su-Qing Zhao, $\mathrm{He}-\mathrm{Lin} \mathrm{Ye}$, et al. Graphene/CeO2 hybrid materials for the simultaneous electrochemical detection of cadmium(II), lead(II), copper(II), and mercury(II). Journal of Electroanalytical Chemistry. 2015;757:235-242.

62. Nassim BB, Mohamed NBH, Mosaab E, et al. Thioglycerolfunctionalized CdSe quantum dots detecting cadmium ions. Sensors and Actuators B: Chemical. 2015;220:1346-1353.

63. Zhaohui Han, Huaiyong Zhu, Jeffrey Shi, et al. Preparation of mesoporous cadmium sulfide nanoparticles with moderate pore size. Journal of Solid State Chemistry. 2007;180(3):902-906.

64. Joseph William K, Egid BM, Yahya MM Makame, et al. Cadmium sulfide quantum dots stabilized by castor oil and ricinoleic acid. Physica E: Low-dimensional Systems and Nanostructures. 2016;76:95-102.

65. Khan Behlol AA, Ahalya P, Anbazhagan V. Fluorescence cadmium sulfide nanosensor for selective recognition of chromium ions in aqueous solution at wide $\mathrm{pH}$ range. Sensors and Actuators B: Chemical. 2015;221:1055-1061.

66. Hu XJ, Liu YG, Zeng GM, et al. Effect of aniline on cadmium adsorption by sulfanilic acid-grafted magnetic graphene oxide sheets. $J$ Colloid Interface Sci. 2014;426:213-220.

67. Kumarswamy YK, Handanahally BM, Yenjerappa AN. Magnificent adsorption capacity of hierarchical mesoporous copper oxide nanoflakes towards mercury and cadmium ions: Determination of analyte concentration by DPASV. Powder Technology. 2014;258:11-19.

68. Yu Zhang, Shen Lin, Wei Zhang, et al. Mesoporous titanium oxide microspheres for high-efficient cadmium sulfide quantum dotsensitized solar cell and investigation of its photovoltaic behavior. Electrochimica Acta. 2014;150:167-172.

69. Qingli Lin, Huaibin Shen, Hongzhe Wang, et al. Cadmium-free quantum dots based violet light-emitting diodes: High-efficiency and brightness via optimization of organic hole transport layers. Organic Electronics. 2015;25:178-183.

70. Moret S, Bécue A, Champod C. Cadmium-free quantum dots in aqueous solution: Potential for fingermark detection, synthesis and an application to the detection of fingermarks in blood on non-porous 
surfaces. Forensic Sci Int. 2013;224(1-3):101-110.

71. Qingyang Liu, Zhongxing Ji, Yiling Bei. Surface-initiated atom transfer radical polymerization of polyamine grafting from magnetic iron oxide submicroparticles for high adsorption capacity of cadmium in aqueous solution. J Colloid Interface Sci. 2013;394:646-651.

72. Wang Z, Liu N, Feng F, et al. Synthesis of cadmium, lead and copper alginate nanobeads as immunosensing probes for the detection of AFP, CEA and PSA. Biosens Bioelectron. 2015;70:98-105.

73. Chensha Li, Yaping Tang, Kefu Yao, et al. Decoration of multiwall nanotubes with cadmium sulfide nanoparticles, Carbon. 2006;44(10):2021-2026.

74. Ambreen Ayub, Abdul Shakoor, Asmat Elahi, et al. Optical and electronic properties of layer-by-layer and composite polyaniline-cadmium selenide quantum dot films. Superlattices and Microstructures. 2015;84:154-164.

75. Hanhong Li, Guangzhao Mao, KY Simon Ng. AFM study of templated growth of cadmium sulfide nanoparticles using pure and mixed arachidate films. Thin Solid Film. 2000;358(1-2):62-72.

76. Ananth DA, Rameshkumar A, Jeyadevi R, et al. Antibacterial potential of rutin conjugated with thioglycolic acid capped cadmium telluride quantum dots (TGA-CdTe QDs). Spectrochim Acta A Mol Biomol Spectrosc. 2015;138:684-692.

77. Seoudi R, Elokr MM, Shabaka AA, et al. Synthesis, characterization, and electrical properties studies of cadmium selenide nanoparticle. Physica B: Condensed Matter. 2008;403(1):152-158.

78. Neetesh K, Viresh D. Fabrication of polymer/cadmium sulfide hybrid solar cells [P3HT:CdS and PCPDTBT:CdS] by spray deposition. $J$ Colloid Interface Sci. 2014;434:181-187.

79. Chen Q, Yin D, Zhu S, et al. Adsorption of cadmium(II) on humic acid coated titanium dioxide. J Colloid Interface Sci. 2012;367(1):241-248.

80. Hong-Wei Liu, Inamur R Laskar, Chin-Ping Huang, et al. Enhanced phosphorescence and electroluminescence in triplet emitters by doping gold into cadmium selenide/zinc sulfide nanoparticles. Thin Solid Films. 2005;489(1-2):296-302.

81. Liubing Huang, Jia Grace Lu. Synthesis, Characterizations and Applications of Cadmium Chalcogenide Nanowires: A Review. Journal of Materials Science \& Technology. 2015;31(6):556-572.

82. Di Zhang, Yeqiong Zhang, Huiyuan Ma, et al. Fabrication of a $12-$ tungstophosphate and cadmium oxide composite film and its properties. Materials Chemistry and Physics. 2014;144(3):369-376.

83. Su Y, Adeleye AS, Huang Y, et al. Simultaneous removal of cadmium and nitrate in aqueous media by nanoscale zerovalent iron (nZVI) and Au doped nZVI particles. Water Res. 2014;63:102-111.

84. Sergej M Rabchynski, Dzmitry K Ivanou, Eugene A Streltsov. Photoelectrochemical formation of indium and cadmium selenide nanoparticles through Se electrode precursor. Electrochemistry Communications. 2004;6(10):1051-1056.

85. Panhwar AH, Kazi TG, Afridi HI, et al. A new solid phase microextraction method using organic ligand in micropipette tip syringe system packed with modified carbon cloth for preconcentration of cadmium in drinking water and blood samples of kidney failure patients. Spectrochim Acta A Mol Biomol Spectrosc. 2015;138:296-302.

86. Xuewu Ge, Yonghong Ni, Huarong Liu, et al. $\gamma$-Irradiation preparation of cadmium selenide nano-particles in ethylenediamine system. Materials Research Bulletin. 2001;36(9):1609-1613.

87. Kátia Duarte, Celine IL Justino, Ana C Freitas, et al. Disposable sensors for environmental monitoring of lead, cadmium and mercury. TrAC Trends in Analytical Chemistry. 2015;64:183-190.
88. Nadtinan Promphet, Poomrat Rattanarat, Ratthapol Rangkupan, et al. An electrochemical sensor based on graphene/polyaniline/polystyrene nanoporous fibers modified electrode for simultaneous determination of lead and cadmium. Sensors and Actuators B: Chemical. 2015;207:526-534.

89. Gunnar F Nordberg, Koji Nogawa, Monica Nordberg. In Handbook on the Toxicology of Metals. In: Gunnar F Nordberg et al. (Ed.), Chapter 32, (4th edn), Academic Press, San Diego, USA. 2015;pp.667-716.

90. Mukesh K Sharma, Narayanan J, Sanjay Upadhyay, et al. Electrochemical immunosensor based on bismuth nanocomposite film and cadmium ions functionalized titanium phosphates for the detection of anthrax protective antigen toxin. Biosensors and Bioelectronics. 2015;74:299-304.

91. Concina I, Memarian N, Selopal GS, et al. Spray-assisted silar deposition of cadmium sulphide quantum dots on metal oxide films for excitonic solar cells. Journal of Power Sources. 2013;240:736-744.

92. Vinod Gupta K, Deepak Pathania, Mohammad Asif, et al. Liquid phase synthesis of pectin-cadmium sulfide nanocomposite and its photocatalytic and antibacterial activity. Journal of Molecular Liquids. 2014; 196:107-112.

93. Wang WS, Zhen L, Shao WZ, et al. Sodium chloride induced formation of square-shaped cadmium molybdate nanoplates. Materials Letters. 2014;131:292-294.

94. Sharma RK, Aditi Puri, Yukti Monga, et al. Newly modified silicabased magnetically driven nanoadsorbent: A sustainable and versatile platform for efficient and selective recovery of cadmium from water and fly-ash ameliorated soil. Separation and Purification Technology. 2014;127:121-130.

95. Ayman M Darwish, Wael H Eisa, Ali A Shabaka, et al. Investigation of factors affecting the synthesis of nano-cadmium sulfide by pulsed laser ablation in liquid environment. Spectrochimica Acta Part A: Molecular and Biomolecular Spectroscopy. 2016;153:315-320.

96. Qu R, Wang X, Wang Z, et al. Metal accumulation and antioxidant defenses in the freshwater fish Carassius auratus in response to single and combined exposure to cadmium and hydroxylated multi-walled carbon nanotubes. J Hazard Mater. 2014;275:89-98.

97. Taher AS, Ahmad M Mohammad, Hassan MA, et al. Development of nano-hydroxyapatite/chitosan composite for cadmium ions removal in wastewater treatment. Journal of the Taiwan Institute of Chemical Engineers. 2014;45(4):1571-1577.

98. Hongmei Dang, Vijay Singh, Suresh Rajaputra, et al. Cadmium sulfide nanowire arrays for window layer applications in solar cells. Solar Energy Materials and Solar Cells. 2014;126:184-191.

99. Savinkina EV, Ilya AZ, Andrey SK, et al. Zinc and cadmium iodide complexes with (thio)amides: Transformations of formamide complexes and effects of substitution on structure and bonding. Polyhedron. 2014;69:68-76.

100. Şükrü Karataş, Fahrettin Yakuphanoğlu. Analysis of electronic parameters of nanostructure copper doped cadmium oxide $/ \mathrm{p}-$-silicon heterojunction. Journal of Alloys and Compounds. 2012;537:6-11.

101. Barbara Fabbri, Andrea Gaiardo, Vincenzo Guidi, et al. Photoactivation of Cadmium Sulfide Films for Gas Sensing. Procedia Engineering. 2014;87:140-143.

102. Dinesh Mohan, Hemant Kumar, Ankur Sarswat, et al. Cadmium and lead remediation using magnetic oak wood and oak bark fast pyrolysis bio-chars. Chemical Engineering Journal. 2014;236:513-528.

103. Hatice Sengül, Thomas L. Life Cycle Inventory of Semiconductor Cadmium Selenide Quantum Dots for Environmental Applications. In: Savage et al. (Eds.), William Andrew Publishing, Oxford. 2014;pp.623-644. 
104. Avijit Paul, Jayeeta Das, Sreemanti Das, et al. Poly (lactide-coglycolide) nano-encapsulation of chelidonine, an active bioingredient of greater celandine (Chelidonium majus), enhances its ameliorative potential against cadmium induced oxidative stress and hepatic injury in mice. Environmental Toxicology and Pharmacology. 2013;36(3):937-947.

105. Ying Li, Wan-Chun Chen, Shen-Ming Chen, et al. Detection of real sample DNA at a cadmium sulfide - chitosan/gelatin modified electrode. Colloids and Surfaces B: Biointerfaces. 2014;113:85-91.

106. BK Sonawane, Vrushali Shelke, Bhole MP, et al. Structural, optical and electrical properties of cadmium zinc oxide films for light emitting devices. Journal of Physics and Chemistry of Solids. 2011;72(12):1442-1446.

107. Areeporn Ontam, Nithima Khaorapapong, Makoto Ogawa. An incorporation of cadmium selenide at organophillic surface of clay mineral. Colloids and Surfaces A: Physicochemical and Engineering Aspects. 2012;411:27-33.

108. Yakuphanoglu F. Synthesis and electro-optic properties of nanosizedboron doped cadmium oxide thin films for solar cell applications. Solar Energy. 2011;85(11):2704-2709.

109. Rempel AA, Kozlova EA, Gorbunova TI, et al. Synthesis and solar light catalytic properties of titania-cadmium sulfide hybrid nanostructures. Catalysis Communications. 2015;68:61-66.

110. Funda Aksoy A, Guvenc Akgul, Hasan Huseyin G, et al. Enhanced diode performance in cadmium telluride-silicon nanowire heterostructures. Journal of Alloys and Compounds. 2015;644:131-139.

111. Jun Pan, Yitai Qian. Synthesis of cadmium chalcogenide nanotubes at room temperature. Materials Letters. 2012;85:132-134.

112. Clament SSN, Thinesh KR, Yogeenth K, et al. Simple and rapid synthesis of Cadmium Oxide $(\mathrm{CdO})$ nanospheres by a microwave-assisted combustion method. Powder Technology. 2011;211(2-3):250-255.

113. Yogesh Kumar K, Muralidhara HB, Arthoba Nayaka Y, et al. Hierarchically assembled mesoporous $\mathrm{ZnO}$ nanorods for the removal of lead and cadmium by using differential pulse anodic stripping voltammetric method. Powder Technology. 2013;239:208-216.

114. Jichun Huang, Tong Liu, Xinwei Liu, et al. Electrochemical capacitive studies of cadmium hydroxide nanowires grown on nickel foam. Journal of Electroanalytical Chemistry. 2013;696:15-19.

115. Ya-Sen Sun, U-Ser Jeng, Keng S Liang, et al. Transitions of domain ordering and domain size in a spherical-forming polystyrene-blockpoly (ethylene oxide) copolymer and its composites with colloidal cadmium sulfide quantum dots. Polymer. 2006;47(4):1101-1107.

116. Guilherme DR, de Lemos LR, da Silva LHM, et al. Application of hydrophobic extractant in aqueous two-phase systems for selective extraction of cobalt, nickel and cadmium. Journal of Chromatography A. 2013;1279:13-19.

117. Aydın C, El-Nasser HM, Yakuphanoglu F, et al. Nanopowder synthesis of aluminum doped cadmium oxide via sol-gel calcination processing. Journal of Alloys and Compounds. 2011;509(3):854-858.

118. Orhan Murat Kalfa, Özcan Yalçınkaya, Ali Rehber Türker. Synthesis of nano $\mathrm{B} 2 \mathrm{O} 3 / \mathrm{TiO} 2$ composite material as a new solid phase extractor and its application to pre concentration and separation of cadmium. Journal of Hazardous Materials. 2009;166(1):455-461.

119. Imran Z, Batool SS, Jamil H, et al. Excellent humidity sensing properties of cadmium titanate nanofibers. Ceramics International. 2013;39(1):457-462.

120. Nan Chen, Yao He, Yuanyuan Su, et al. The cytotoxicity of cadmiumbased quantum dots. Biomaterials. 2012;33(5):1238-1244.

121. Vinodkumar R, Lethy KJ, Arunkumar PR, et al. Effect of cadmium oxide incorporation on the microstructural and optical properties of pulsed laser deposited nanostructured zinc oxide thin films. Materials Chemistry and Physics. 2010;121(3):406-413.

122. Saravanan M, Sabari Girisun TC. Nonlinear optical absorption and optical limiting properties of cadmium ferrite. Materials Chemistry and Physics. 2015;160:413-419.

123. Chenhuan Li, Suolong Yang, Baozhan Zheng, et al. Cadmium sulfide nanotubes thin films: Characterization and photoelectrochemical behavior. Thin Solid Films. 2012;520(7):2520-2525.

124. Alexander N Kudlash, Svetlana A Vorobyova, Anatoly I Lesnikovich, et al. Optical properties of cadmium sulfide colloidal dispersions prepared by interphase synthesis. Optical Materials. 2008;30(8):1304-1309.

125. Mohamed E Mahmoud, Gehan M Nabil, Sarah ME Mahmoud. High performance nano-zirconium silicate adsorbent for efficient removal of copper (II), cadmium (II) and lead (II). Journal of Environmental Chemical Engineering. 2015;3(2):1320-1328.

126. Dae-Jin Kim, Ju-Hyun Lee, Jae-Woong Yu, et al. Low temperature non-alkylphosphine based synthesis of cadmium selenide nanocrystals. Colloids and Surfaces A: Physicochemical and Engineering Aspects. 2008;313-314:211-215.

127. Jinmei Luo, Haihua Bai, Peihui Yang, et al. One-pot aqueous synthesis of germanium-doped cadmium sulfide quantum dots as fluorescent probes for cell imaging. Materials Science in Semiconductor Processing. 2015;34:1-7.

128. Kuanping Gong. Vertically-aligned sandwich nanowires enhance the photoelectrochemical reduction of hydrogen peroxide: Hierarchical formation on carbon nanotubes of cadmium sulfide quantum dots and Prussian blue nanocoatings. Journal of Colloid and Interface Science. 2015;449:80-86.

129. Hu X, Chen Q, Jiang L, et al. Combined effects of titanium dioxide and humic acid on the bioaccumulation of cadmium in Zebrafish. Environ Pollut. 2011;159(5):1151-1158.

130. Luo L, Ma C, Ma Y, et al. New insights into the sorption mechanism of cadmium on red mud. Environ Pollut. 2011;159(5):1108-1113.

131. Ma X, Cui W, Yang L, et al. Efficient biosorption of lead (II) and cadmium (II) ions from aqueous solutions by functionalized cell with intracellular $\mathrm{CaCO} 3$ mineral scaffolds. Bioresource Technology. 2015;185:70-78.

132. Bao L, William WH, Sheng-Han L, et al. Cadmium ion soaking treatment for solution processed CuInSxSe2-x solar cells and its effect on defect properties. Solar Energy Materials and Solar Cells. 2011;95(8):2384-2389.

133. Qiaofeng H, Jin Z, Lei W, et al. Synthesis of CdS multipods from cadmium xanthate in ethylenediamine solution. Particuology. 2015;19:45-52.

134. Mahato S, Kar AK. Structural, optical and electrical properties of electrodeposited cadmium selenide thin films for applications in photodetector and photoelectrochemical cell. Journal of Electroanalytical Chemistry. 2015;742:23-29.

135. Du AJ, Sun DD, Leckie JO. Sequestration of cadmium ions using titanate nanotube. Journal of Hazardous Materials. 2011;187(1-3):401-406.

136. Nan D, Lei R, Weifu S, et al. In situ synthesis of binary cobaltruthenium nanofiber alloy counter electrode for electrolyte-free cadmium sulfide quantum dot solar cells. Journal of Power Sources. 2015;284:162-169.

137. Svetlana NA, Pavel AV, Nina II, et al. Synthesis and structural characterization of novel zinc(II) and cadmium(II) complexes with pyridine-phosphine chalcogenide ligands. Journal of Organometallic Chemistry. 2011;696(10):2053-2058. 
138. Cheng X, Tjong SC, Li RKY. 1-Synthesis and optical properties of cadmium sulfide/polymer nanocomposite particles. Physical Properties and Applications of Polymer Nanocomposites. 2010;3-30.

139. Toshiyuki E, Eiichi S, Purkhet A, et al. Conventional X-ray fluorescence camera with a cadmium-telluride detector and its application to cancer diagnosis, Nuclear Instruments and Methods in Physics Research Section A: Accelerators, Spectrometers. Detectors and Associated Equipment. 2011;635(1):108-115.

140. Rokas D, Andrius P, Kęstutis A. X-ray sensitivity of small organic molecule and zinc cadmium sulfide mixture layers deposited using thermal melting technique. Organic Electronics. 2015;18:37-43.

141. Hiroshi, Eiichi S, Osahiko H, et al. Application of an oscillation-type linear cadmium telluride detector to enhanced gadolinium $\mathrm{K}$-edge computed tomography. Nuclear Instruments and Methods in Physics Research Section A: Accelerators, Spectrometers, Detectors and Associated Equipment. 2011;632(1):142-146.

142. Manohara BM, Nagabhushana H, Thyagarajan K, et al. Spectroscopic and luminescence studies of $\mathrm{Cr} 3+$ doped cadmium silicate nanophosphor. Journal of Luminescence. 2015;161:247-256.

143. Gopi S, Ruchika B, Nancy M, et al. Influence of lead and cadmium fluoride variation on white light emission characteristics in oxyfluoride glasses and glass-ceramics. Journal of Luminescence. 2015;159:38-46.

144. Srivastava AK, Pandey S, Sood KN, et al. Novel growth morphologies of nano- and micro-structured cadmium oxide. Materials Letters. 2008;62(4-5):727-730.

145. Hassan ML, Ali AF. Synthesis of nanostructured cadmium and zinc sulfides in aqueous solutions of hyperbranched polyethyleneimine. Journal of Crystal Growth. 2008;310(24):5252-5258.

146. Silva MFO, Paniago RM, Miquita DR, et al. Determination of the band alignment of multi-walled carbon nanotubes decorated with cadmium sulfide. Applied Surface Science. 2014;321:283-288.

147. Deepa M, Ruchi G, Joshi AG, et al. Enhanced photoelectrochemistry and interactions in cadmium selenide-functionalized multiwalled carbon nanotube composite films. Electrochimica Acta. 2010;55(22):6731-6742.

148. Li KG, Chen JT, Bai SS, et al. Intracellular oxidative stress and cadmium ions release induce cytotoxicity of unmodified cadmium sulfide quantum dots. Toxicol In Vitro. 2009;23(6):1007-1013.

149. Hong L, Meixian L, Dragan M. Simultaneous Determination of Copper, Lead, and Cadmium Ions at a Mo6S9-xIx Nanowires Modified Glassy Carbon Electrode Using Differential Pulse Anodic Stripping Voltammetry. Electrochimica Acta. 2015;154:184-189.

150. Harpreet K, Jashanpreet S, Randhawa BS. Essence of superparamagnetism in cadmium ferrite induced by various organic fuels via novel solution combustion method. Ceramics International. 2014;40(8):12235-12243.

151. Dong L, Zhu Z, Ma H, et al. Simultaneous adsorption of lead and cadmium on MnO2-loaded resin. J Environ Sci. 2010;22(2):225-229.

152. Zizhong Z, Mengyan L, Wei C, et al. Immobilization of lead and cadmium from aqueous solution and contaminated sediment using nano-hydroxyapatite. Environmental Pollution. 2010;158(2):514-519.

153. Armstrong KC, Tatum CE, Dansby-Sparks RN, et al. Individual and simultaneous determination of lead, cadmium, and zinc by anodic stripping voltammetry at a bismuth bulk electrode. Talanta. 2010;82(2):675-680.

154. Sawant VS, Shinde SS, Deokate RJ, et al. Effect of calcining temperature on electrical and dielectric properties of cadmium stannate. Applied Surface Science. 2009;255(13-14):6675-6678.

155. Biljana P. The Urbach-Martienssen absorption tails in the optical spectra of semiconducting variable-sized zinc selenide and cadmium selenide quantum dots in thin film form. Materials Chemistry and Physics. 2010;119(3):367-376.

156. Peyrot C, Gagnon C, Gagné F, et al. Effects of cadmium telluride quantum dots on cadmium bioaccumulation and metallothionein production to the freshwater mussel, Elliptio complanata. Comparative Biochemistry and Physiology Part C: Toxicology \& Pharmacology. 2009;150(2):246-251.

157. Jiayin Y, Markus D, Youyong X, et al. Cadmium selenide nanowires within core-shell cylindrical polymer brushes: Synthesis, characterization and the double-loading process. Polymer. 2008;49(6):1547-1554.

158. Zhiqiang W, Hui W, Zhihao Z, et al. Electrochemical determination of lead and cadmium in rice by a disposable bismuth/electrochemically reduced graphene/ionic liquid composite modified screen-printed electrode. Sensors and Actuators B: Chemical. 2014;199:7-14.

159. Jun Z, Xuefeng Q. Necklace-like nanostructures of cadmium hydroxide: Controlled synthesis with bubble-template and its separation property on dye. Solid State Sciences. 2008;10(11):1577-1583.

160. Zhaohui Han, Huaiyong Zhu, Kyle R Ratinac, et al. Nanocomposites of layered clays and cadmium sulfide: Similarities and differences in formation. structure and properties. Microporous and Mesoporous Materials. 2008;108(1-3):168-182.

161. O'Brien P, EW Hill, MA Malik, et al. Chemical bath deposition of cadmium sulphide on silicon nitride: Influence of surface treatment on film growth. Materials Letters. 2007;61(1):284-287.

162. Ali Badawi, Al-Hosiny N, Abdallah S, et al. Single wall carbon nanotube/titania nanocomposite photoanodes enhance the photovoltaic performance of cadmium selenide quantum dot-sensitized solar cells. Materials Science in Semiconductor Processing. 2014;26:162-168.

163. Bassaid S, Chaib M, Omeiri S, et al. Photocatalytic reduction of cadmium over $\mathrm{CuFeO} 2$ synthesized by sol-gel. Journal of Photochemistry and Photobiology A: Chemistry. 2009;201(1):62-68.

164. Li J, Li J, Li Y. Cadmium removal from wastewater by sponge iron sphere prepared by charcoal direct reduction. J Environ Sci. 2009;21(Suppl 1):S60-S64.

165. Haibing Li, Yan Zhang, Xiaoqiong Wang. L-Carnitine capped quantum dots as luminescent probes for cadmium ions. Sensors and Actuators B: Chemical. 2007;127(2):593-597.

166. Ali Kamel Mohsin, Noriah Bidin. Effect of cadmium sulfide thickness on electron beam-deposited titania/cadmium sulfide nanocomposite films. Materials Science in Semiconductor Processing. $2014 ; 24: 208-214$

167. Lijie Zhang, Hongfei Yu, Wei Cao, et al. Antimony doped cadmium selenium nanobelts with enhanced electrical and optoelectrical properties. Applied Surface Science. 2014;307:608-614.

168. Xiaohong S Li, Glen E Fryxell, Mark H Engelhard, et al. The synthesis of cadmium doped mesoporous TiO2. Inorganic Chemistry Communications. 2007;10(6):639-641.

169. Zhi-liang ZHU, Hong-mei MA, Rong-hua ZHANG, et al. Removal of cadmium using MnO2 loaded D301 resin. Journal of Environmental Sciences. 2007;19(6):652-656.

170. Ronghui Xu, Yongxian Wang, Guangqiang Jia, et al. Zinc blende and wurtzite cadmium sulfide nanocrystals with strong photoluminescence and ultrastability. Journal of Crystal Growth. 2007;299(1):28-33.

171. Manohara BM, Nagabhushana H, Sunitha DV, et al. Synthesis and luminescent properties of Tb3+ activated cadmium silicate nanophosphor. Journal of Alloys and Compounds. 2014;592:319-327.

172. Jeyadevi R, Sivasudha T, Rameshkumar A, et al. Enhancement of anti arthritic effect of quercetin using thioglycolic acid-capped cadmium 
telluride quantum dots as nanocarrier in adjuvant induced arthritic Wistar rats. Colloids and Surfaces B: Biointerfaces. 2013;112:255-263.

173. Deng-wei J, Wen-dong T, Chan-juan X, et al. Study on photocatalytic hydrogen production in simulated organic pollutants over cadmium sulfide composite photocatalyst. Journal of Fuel Chemistry and Technology. 2011;39(2):135-139.

174. Osipovich NP, Poznyak SK. Underpotential deposition of cadmium adatoms on Te and CdTe. Electrochimica Acta. 2006;52(3):996-1002

175. Anderson Fuzer M, de Oliveira AP, de Lima GM, et al. The effect of different annealing temperatures on tin and cadmium telluride phases obtained by a modified chemical route. Materials Research Bulletin. 2014;47(11):3844-3849.

176. Hankare PP, Sanadi KR, Pandav RS, et al. Structural, electrical and magnetic properties of cadmium substituted copper ferrite by sol-gel method. Journal of Alloys and Compounds. 2012;540:290-296.

177. Qingmin Zhang, Fuzhi Huang, Yan Li. Cadmium sulfide nanorods formed in microemulsions. Colloids and Surfaces A: Physicochemical and Engineering Aspects. 2005;257-258:497-501.

178. Roushdy N, Farag AAM, Abdel Rafea M, et al. Influence of cadmium content on the microstructure characteristics of dip coated nano crystalline $\mathrm{Zn} 1-\mathrm{xCdxS}(0 \leqslant \mathrm{x} \leqslant 0.9)$ and their hetero junction applications. Super lattices and Microstructures. 2013;62:97-109.

179. Pavan K Narayanam, Purvesh Soni, Mohanta P, et al. Effect of heat treatment on the photoluminescence of CdS nanocrystallites in cadmium-rich organic Langmuir Blodgett matrix. Materials Chemistry and Physics. 2013;139(1):196-209.

180. Sachin A Pawar, Rupesh S Devan, Dipali S Patil, et al. Improved solar cell performance of chemosynthesized cadmium selenide pebbles. Electrochimica Acta. 2013;98:244-254.

181. Visa M, Duta A. Methyl-orange and cadmium simultaneous removal using fly ash and photo-Fenton systems. J Hazard Mater. 2013;244-245:773-779.

182. Wei-Min Zhang, Na Li, De-Hui Tang, et al. Tubular CdS with mesoporous structure self-templated by cadmium complexes of oleate. Microporous and Mesoporous Materials. 2011;143(1):249-251.

183. Junchang Zhao, Jihuai Wu, Fuda Yu, et al. Improving the photovoltaic performance of cadmium sulfide quantum dots-sensitized solar cell by graphene/titania photoanode. Electrochimica Acta. 2013;96:110-116.

184. Moloto MJ, Malik MA, O’Brien P, et al. Synthesis and characterisation of some $\mathrm{N}$-alkyl/aryl and $\mathrm{N}, \mathrm{N}^{\prime}$-dialkyl/aryl thiourea cadmium(II) complexes: the single crystal $\mathrm{X}$-ray structures of $[\mathrm{CdCl} 2(\mathrm{CS}(\mathrm{NH} 2)$ $\mathrm{NHCH} 3) 2] n$ and [CdCl2(CS(NH2)NHCH2CH3)2]. Polyhedron. 2003;22(4):595-603.

185. Rameshkumar A, Sivasudha T, Jeyadevi R, et al. In vitro antioxidant and antimicrobial activities of Merremia emarginata using thio glycolic acid-capped cadmium telluride quantum dots. Colloids and Surfaces B Biointerfaces. 2013;101:74-82.

186. Marx Nirmal R, Pandian K, Sivakumar K. Cadmium (II) pyrrolidine dithiocarbamate complex as single source precursor for the preparation of CdS nanocrystals by microwave irradiation and conventional heating process. Applied Surface Science. 2011;257(7):2745-2751.

187. Nisha KD, Navaneethan M, Hayakawa Y, et al. Influence of lanthanide ion on the morphology and luminescence properties of cadmium sulphide nanocrystals. Journal of Alloys and Compounds. 2011;509(19):5816-5821.

188. Ahamefula UC, Sulaiman MY, Ibarahim Z, et al. Low-Temperature Synthesis and Characterisation of Ultra-Small Cadmium Selenide Quantum Dots in Octadecene Solution. Energy Procedia. 2012;25:62-69.

189. Saim Emin, Masatoshi Yanagida, Wenqin Peng, et al. Evaluation of carrier transport and recombinations in cadmium selenide quantum- dot-sensitized solar cells. Solar Energy Materials and Solar Cells. 2012;101:5-10.

190. Cheng-min Shen, Xiao-gang Zhang, Hu-lin Li. Effect of $\mathrm{pH}$ on the electrochemical deposition of cadmium selenide nanocrystal films. Materials Science and Engineering: B. 2001;84(3):265-270.

191. Gupta N, Pal B. The synthesis, structure, optical and photocatalytic properties of silica-coated cadmium sulfide nano composites of different shapes. Journal of Colloid and Interface Science. 2012;368(1):250-256.

192. Maxim A Nasalevich, Ekaterina A Kozlova, Tatyana P Lyubina, et al. Photocatalytic oxidation of ethanol and isopropanol vapors on cadmium sulfide. Journal of Catalysis. 2012;287:138-148.

193. Taukeer Khan M, Ranoo Bhargav, Amarjeet Kaur, et al. Effect of cadmium sulphide quantum dot processing and post thermal annealing on P3HT/PCBM photovoltaic device. Thin Solid Films 2010;519(3):1007-1011

194. Ashoka S, Nagaraju G, Thipperudraiah KV, et al. Controlled synthesis of cadmium carbonate nano wires, nanoribbons, nanorings and sphere like architectures via hydrothermal method. Materials Research Bulletin. 2010;45(11):1736-1740.

195. Maochang Liu, Yuanchang Du, Lijng Ma, et al. Manganese doped cadmium sulfide nanocrystal for hydrogen production from water under visible light. International Journal of Hydrogen Energy. 2012;37(1):730-736

196. Vanalakar SA, Mali SS, Pawar RC, et al. Synthesis of cadmium sulfide spongy balls with nanoconduits for effective light harvesting. Electrochimica Acta. 2011;56(6):2762-2768

197. Manabu Watanabe, Eiichi Sato, Purkhet Abderyim, Abulajiang Abudurexiti, Osahiko Hagiwara, et al. First demonstration of 10 $\mathrm{keV}$-width energy-discrimination $\mathrm{K}$-edge radiography using a cadmium-telluride X-ray camera with a tungsten-target tube. Nuclear Instruments and Methods in Physics Research Section A: Accelerators. 2011;637(1):171-177.

198. Xiao-Li Yang, Jun Zhang, Shi-Bin Ren et al. A two-dimensional layered cadmium sulfide superlattice constructed from cappedsupertetrahedral C1 clusters. Inorganic Chemistry Communications. 2010;13(1):1337-1339.

199. Su Y, Peng F, Jiang $\mathrm{Z}$ et al. In vivo distribution, pharmacokinetics, and toxicity of aqueous synthesized cadmium-containing quantum dots. Biomaterials. 2011;32(25):5855-5862.

200. Zhiyue Han, Jingchang Zhang, Xiuying Yang, Weiliang Cao Synthesis and application in solar cell of poly(3-octylthiophene)/cadmium sulfide nanocomposite. Solar Energy Materials and Solar Cells. 2011;95(2):483-490

201. Yinxiao Du, Guang-cheng Li Facile synthesis of cadmium selenide nanowires and their optical properties. Physica E: Low-dimensional Systems and Nanostructures. 2011;43(4):994-997.

202. Pulakesh Bera, Chong-Hyeak Kim, Sang II Seok Synthesis of nanocrystalline CdS from cadmium (II) complex of Sbenzyl dithiocarbazate as a precursor. Solid State Sciences. 2010;12(10):1741-1747.

203. Kolezynski A FP-LAPW study of anhydrous cadmium and silver oxalates: electronic structure and electron density topology. Physica B: Condensed Matter. 2010;405(17):3650-3657.

204. Jean-Pierre Veder, Ayman Nafady, Graeme Clarke et al. A flow cell for transient voltammetry and in situ grazing incidence $\mathrm{X}$-ray diffraction characterization of electro crystallized cadmium (II) tetracyanoquinodimethane. Electrochimica Acta. 2011;56(3):1546-1553.

205. Eiichi Sato, Yuichi Sato, Shigeru Ehara et al. First demonstration of iodine mapping in nonliving phantoms using an X-ray fluorescence computed tomography system with a cadmium telluride detector and 
a tungsten-target tube. Nuclear Instruments and Methods in Physics Research Section A: Accelerators, Spectrometers, Detectors and Associated Equipment. 2011;638(1):187-191.

206. Pulakesh Bera, Chong-Hyeak Kim, Sang II Seok High-yield synthesis of quantum-confined CdS nanorods using a new dimeric cadmium (II) complex of S-benzyldithiocarbazate as single-source molecular precursor. Solid State Sciences. 2010;12(4):532-535.

207. Hwang GH, Han WK, Hong SJ et al. Determination of trace amounts of lead and cadmium using a bismuth/glassy carbon composite electrode. Talanta. 2009;77(4):1432-1436.

208. Malekigorji M, Curtis ADM, Hoskins C The Use of Iron Oxide Nanoparticles for Pancreatic Cancer Therapy. J Nanomed Res. 2014;1(1):00004.

209. Cruje C, Chithrani DB Polyethylene Glycol Density and Length Affects Nanoparticle Uptake by Cancer Cells. J Nanomed Res. 2014;1(1):00006

210. Malekigorji M, Hoskins C, Curtis T et al. Enhancement of the Cytotoxic Effect of Anticancer Agent by Cytochrome c Functionalised Hybrid Nanoparticles in Hepatocellular Cancer Cells. J Nanomed Res. 2014;1(2):00010.

211. Mohamed Bououdina, Aqeel Aziz Dakhel, Mohammad ElHilo, Dalaver H Anjum, Mohammed Benali, et al. Revealing a room temperature ferromagnetism in cadmium oxide nanoparticles: an experimental and first-principles study. RSC Adv 2015;5:33233-33238.

212. Blum JL, Edwards JR, Prozialeck WC et al. Effects of Maternal Exposure to Cadmium Oxide Nanoparticles During Pregnancy on Maternal and Offspring Kidney Injury Markers Using a Murine Model. J Toxicol Environ Health A. 2015;78(12):711-724.

213. Sachet E, Shelton CT, Harris JS et al. Dysprosium-doped cadmium oxide as a gateway material for mid-infrared plasmonics. Nat Mater. 2015;14(4):414-420.

214. El Sayed AM, El-Sayed S, Morsi WM et al. Synthesis, characterization, optical, and dielectric properties of polyvinyl chloride/cadmium oxide nanocomposite films. Polym Compos. 2014;35(9):1842-1851

215. Lim I, Shinde DV, Patil SA et al. Interfacial Engineering of CdOCdSe 3D Microarchitectures with in situ Photopolymerized PEDOT for an Enhanced Photovoltaic Performance. Photochemistry and Photobiology. 2015;91(4):780-785.

216. Van TK, Pham LQ, Kim do Y et al. Formation of a CdO Layer on $\mathrm{CdS} / \mathrm{ZnO}$ Nanorod Arrays to Enhance their Photoelectrochemical Performance. ChemSusChem. 2014;7(12):3505-3512.

217. Shi Y, Chen Y, Tian G et al. Hierarchical Ag/Ag2S/CuS Ternary Heterostructure Composite as an Efficient Visible-Light Photocatalyst. Chem Cat Chem. 2015;7(11):1684-1690.

218. Kamaljot Kaur, Savita Chaudhary, Sukhjinder Singh et al. Imine modified $\mathrm{ZnO}$ nanoparticles: a luminescent chemodosimeter for $\mathrm{Al} 3+$ and $\mathrm{S} 2-$ ions based on ligand displacement reaction. New J Chem. 2015;39:1773-1782.
219. Sanjay B Kokane, Sartale SD, Girija KG et al. Photocatalytic performance of Pd decorated $\mathrm{TiO} 2-\mathrm{CdO}$ composite: Role of in situ formed $\mathrm{CdS}$ in the photocatalytic activity. International Journal of Hydrogen Energy. 2015;40(39):13431-13442.

220. Majeed I, Amtiaz Nadeem M, Al-Oufi M et al. On the role of metal particle size and surface coverage for photo-catalytic hydrogen production: A case study of the $\mathrm{Au} / \mathrm{CdS}$ system. Applied Catalysis B: Environmental. 2016;182:266-276.

221. Dhatshanamurthi P, Subash B, Shanthi M Investigation on UV-A light photocatalytic degradation of an azo dye in the presence of $\mathrm{CdO} /$ $\mathrm{TiO} 2$ coupled semiconductor. Materials Science in Semiconductor Processing. 2015;35:22-29.

222. Sachin G Ghugal, Suresh S Umare, Rajamma Sasikala A stable, efficient and reusable $\mathrm{CdS}$ ? $\mathrm{SnO} 2$ heterostructured photocatalyst for the mineralization of Acid Violet 7 dye. Applied Catalysis A: General. 2015;496:25-31.

223. Sudheer Khan S Enhancement of visible light photocatalytic activity of $\mathrm{CdO}$ modified $\mathrm{ZnO}$ nanohybrid particles. J Photochem Photobiol B. 2015;142:1-7.

224. Lei M, Bi K, Zhang YB et al. Highly selective growth of TiO2 nanoparticles on one tip of CdS nanowires. Journal of Alloys and Compounds. 2015;646:1004-1008.

225. Ling LY, Yan TL, Chu Xiong $\mathrm{H}$ et al. Temperature-dependent photoluminescence and mechanism of CdS thin film grown on $\mathrm{Si}$ nanoporous pillar array. Applied Surface Science. 2015;349:219-223.

226. Devadoss I, Muthukumaran $\mathrm{S}$ Influence of $\mathrm{Cu}$ doping on the microstructure, optical properties and photoluminescence features of $\mathrm{Cd} 0.9 \mathrm{Zn} 0.1 \mathrm{~S}$ nanoparticles. Physica E: Low-dimensional Systems and Nanostructures. 2015;72:111-119.

227. Soylu M, Ahmed A Al-Ghamdi, Yakuphanoglu F Transparent CdO/n$\mathrm{GaN}(0001)$ heterojunction for optoelectronic applications. Journal of Physics and Chemistry of Solids. 2015;85:26-33.

228. Sonawane NB, Ahire RR, Gurav KV et al. PEDOT:PSS shell on CdS nanowires: Room temperature LPG sensor. Journal of Alloys and Compounds. 2014;592:1-5.

229. Nasser AM Barakat, Enas Ahmed, Mohammad Ali A et al. Ag, Zn and Cd-doped titanium oxide nanofibers as effective photocatalysts for hydrogen extraction from ammonium phosphates. Journal of Molecular Catalysis A: Chemical. 2015;409:117-126.

230. Heidari A Simulation of interaction of light and Iridium nanoparticles using 3D finite element method (FEM) as an optothermal cancer cells treatment. International Journal of Theoretical, Computational and Mathematical Chemistry. 2015;1(1):15-20. 